\title{
The impact of air-sea coupling and ocean biases on the seasonal cycle of southern West African precipitation
}

\author{
Caroline M. Wainwright ${ }^{1,2}$ (D) Linda C. Hirons ${ }^{2} \cdot$ Nicholas P. Klingaman $^{2} \cdot$ Richard P. Allan $^{1,3} \cdot$ Emily Black $^{1,2}$. \\ Andrew G. Turner ${ }^{2}$
}

Received: 21 September 2018 / Accepted: 4 September 2019 / Published online: 16 September 2019

(c) The Author(s) 2019

\begin{abstract}
The biannual seasonal rainfall regime over the southern part of West Africa is characterised by two wet seasons, separated by the 'Little Dry Season' in July-August. Lower rainfall totals during this intervening dry season may be detrimental for crop yields over a region with a dense population that depends on agricultural output. Coupled Model Intercomparison Project Phase 5 (CMIP5) models do not correctly capture this seasonal regime, and instead generate a single wet season, peaking at the observed timing of the Little Dry Season. Hence, the realism of future climate projections over this region is questionable. Here, the representation of the Little Dry Season in coupled model simulations is investigated, to elucidate factors leading to this misrepresentation. The Global Ocean Mixed Layer configuration of the Met Office Unified Model is particularly useful for exploring this misrepresentation, as it enables separating the effects of coupled model ocean biases in different ocean basins while maintaining air-sea coupling. Atlantic Ocean SST biases cause the incorrect seasonal regime over southern West Africa. Upper level descent in August reduces ascent along the coastline, which is associated with the observed reduction in rainfall during the Little Dry Season. When coupled model Atlantic Ocean biases are introduced, ascent over the coastline is deeper and rainfall totals are higher during July-August. Hence, this study indicates detrimental impacts introduced by Atlantic Ocean biases, and highlights an area of model development required for production of meaningful climate change projections over the West Africa region.
\end{abstract}

Keywords Little Dry Season · Coupled models · Atlantic SST bias · West African monsoon · Precipitation · Seasonal cycle

\section{Introduction}

The southern part of West Africa is a highly populated region, with many people dependent upon seasonal rainfall for farming activities and domestic purposes. While the majority of West Africa experiences one primary monsoonal wet season per year (Sultan and Janicot 2003; Nicholson

Electronic supplementary material The online version of this article (https://doi.org/10.1007/s00382-019-04973-0) contains supplementary material, which is available to authorized users.

Caroline M. Wainwright

c.wainwright@ reading.ac.uk

1 Department of Meteorology, University of Reading, Reading, UK

2 NCAS, University of Reading, Reading, UK

3 National Centre for Earth Observation (NCEO), Reading, UK
2013), a region in the southern part of West Africa, encompassing parts of southern Ghana, Benin, Togo, Ivory Coast and south-west Nigeria experiences two wet seasons (Herrmann and Mohr 2011; Liebmann et al. 2012; Parker and Diop-Kane 2017). The northward progression of the tropical rain belt in boreal spring brings the first wet season from April-June; the second wet season in September and October is associated with the returning southward progression of the tropical rain belt in boreal autumn. Separating the two wet seasons is the 'Little Dry Season' (LDS): a period of lower and less frequent rainfall (Adejuwon and Odekunle 2006; Odekunle and Eludoyin 2008; Chineke et al. 2010; Parker and Diop-Kane 2017). The length and severity of the LDS has important socio-economic implications: while a shorter and less intense LDS is useful for weeding and spraying crops with pesticide, a longer and more intense LDS can lead to crop failure (Adejuwon and Odekunle 2006; Odekunle 2007). 
A number of interactions between the LDS and other meteorological phenomena have been proposed (Odekunle 2007). Years with cooler than average sea surface temperatures (SSTs) over the Gulf of Guinea have an increased landsea thermal contrast, strengthening the monsoon southwesterlies and shifting the tropical rain belt further inland, giving a drier LDS (Adejuwon and Odekunle 2006). More locally, anomalously cool SST (when compared with the latitudinal average) is consistently observed in July-September over the northern Gulf of Guinea $\left(8^{\circ} \mathrm{W}-2^{\circ} \mathrm{E}, 3^{\circ} \mathrm{N}\right.$ to the coastline, see Fig. 1d-f), adjacent to the region that experiences the LDS (Parker and Diop-Kane 2017), which increases static stability over the region, suppressing convection and limiting rainfall (Odekunle and Eludoyin 2008; Odekunle 2010). This cool SST results from local coastal upwelling (Parker and Diop-Kane 2017), strengthened by the summer intensification of the eastward Guinea Current, which leads to shoaling of the thermocline near the northern coast of the Gulf of Guinea, and the advection of cold coastally upwelled water by the South Equatorial Current (northward extension of the cold Benguela Current; Odekunle and Eludoyin 2008). Odekunle (2007) identified strong relationships between SSTs in the Gulf of Guinea, the source regions of the Guinea and Benguela current and the LDS, with warmer SSTs associated with higher rainfall during the LDS (i.e. less intense LDS). Parker and Diop-Kane (2017) highlighted the role of high pressure over the Gulf of Guinea and the St Helena high pressure cell: the effect of this high pressure extends to the coastal regions, where the associating sinking motion reduces convection during the LDS.

Coupled global climate models (CGCMs) are used for sensitivity tests that explore the physics of meteorological phenomena, as well as producing projections of future climate change. Many studies have identified and explored deficiencies in the representation of the West African Monsoon in atmosphere-only climate model simulations (AGCMs) and CGCMs (Cook and Vizy 2006; Roehrig et al. 2013; Flato et al. 2013). Roehrig et al. (2013) assessed the representation of the West African Monsoon in CGCMs. They found that both CMIP3 and CMIP5 coupled models exhibit sizable biases in the mean position of the West African Monsoon. Furthermore, they note that most models contain a warm bias in the equatorial Atlantic, and a southward shift of the ITCZ in coupled models; this southward bias is also investigated in other studies (Siongco et al. 2015; James et al. 2018; Steinig et al. 2018). CGCMs also have biased representations of prominent modes of variability (Sperber et al. 2017), and the large mesoscale propagating systems, which bring much of the boreal summer rainfall over West Africa and the Sahel (Mathon et al. 2002; Roehrig et al. 2013). Furthermore, the Saharan Heat Low in CGCMs is generally weaker than in reanalyses and placed too far southwest (Dixon et al. 2017). Models also fail to reproduce important coupling between Sahel rainfall and large-scale dynamics over West Africa, including the African Easterly Jet (Whittleston et al. 2017) and African Easterly Waves (Martin and Thorncroft 2015). Recently, Lauer et al. (2018) used the Earth System Model Evaluation Tool (ESMValTool) to assess the performance of the updated versions of 4 Earth System Models (HadGEM, EC-Earth, MPI-ESM and CNRM). While there are some improvements in these model versions compared to their CMIP5 counterparts, significant biases persist in the representation of the West African Monsoon. Most models still have significant difficulties simulating African Easterly Waves, similar to the CMIP5 models (Martin and Thorncroft 2015).

In their assessment of the representation of rainfall seasonality in AMIP and CMIP5 models across Africa, Dunning et al. (2017) identified a further deficiency in the representation of the seasonal cycle of precipitation over the southern part of West Africa in CGCMs. While AGCMs, forced by observed SSTs, correctly produced wet seasons in April-June and September-October, separated by the LDS, the CGCMs generated a single wet season, with a single rainfall peak in July-August, coincident with the observed LDS. They proposed that this was due to the incorrect SST seasonal cycle over the northern Gulf of Guinea in CGCMs. Over the northern Gulf of Guinea, SST cools from April/ May to August due to oceanic upwelling and transport of cool water by ocean currents (e.g. Fig. 1a-f; Odekunle and Eludoyin 2008). However, CGCMs do not capture this cooling, shown in Dunning et al. (2017) and in Fig. 1g-1, where the increasing warm bias over this region is apparent. This may be related to insufficient upwelling, or coarse ocean model horizontal resolution leading to inaccurate representation of the Guinea Current. The misrepresentation of the seasonality over the southern part of West Africa questions the realism of climate projections in this region, as well as the utility of CGCMs for establishing the driving mechanisms of and exploring teleconnections to the LDS. Failure to capture the LDS and associated processes may indicate more general difficulties with the representation of monsoon dynamics, for example insufficient northward progression of the monsoon. Dike et al. (2015) also identified the lack of the LDS over Nigeria in one coupled climate model, but did not investigate this discrepancy further. While other studies have explored deficiencies in the representation of the wider West African Monsoon (e.g. Roehrig et al. 2013), none have explicitly investigated the representation of the LDS in global climate models. Here, we aim to investigate possible factors that lead to this deficiency. Such factors may also adversely affect model simulations in other regions where similar processes operate.

Adejuwon and Odekunle (2006), Odekunle and Eludoyin (2008) and Parker and Diop-Kane (2017) all highlight the role of cool SSTs in the Gulf of Guinea on the seasonal cycle 
Fig. 1 a-f Mean monthly SST (Smith and Murphy 2007) for April-September. g-l Difference between mean surface temperature from GC2-GC2 (fully coupled configuration of the MetUM), at N216 resolution, and observed SST (Smith and Murphy 2007) for AprilSeptember
Observed SST
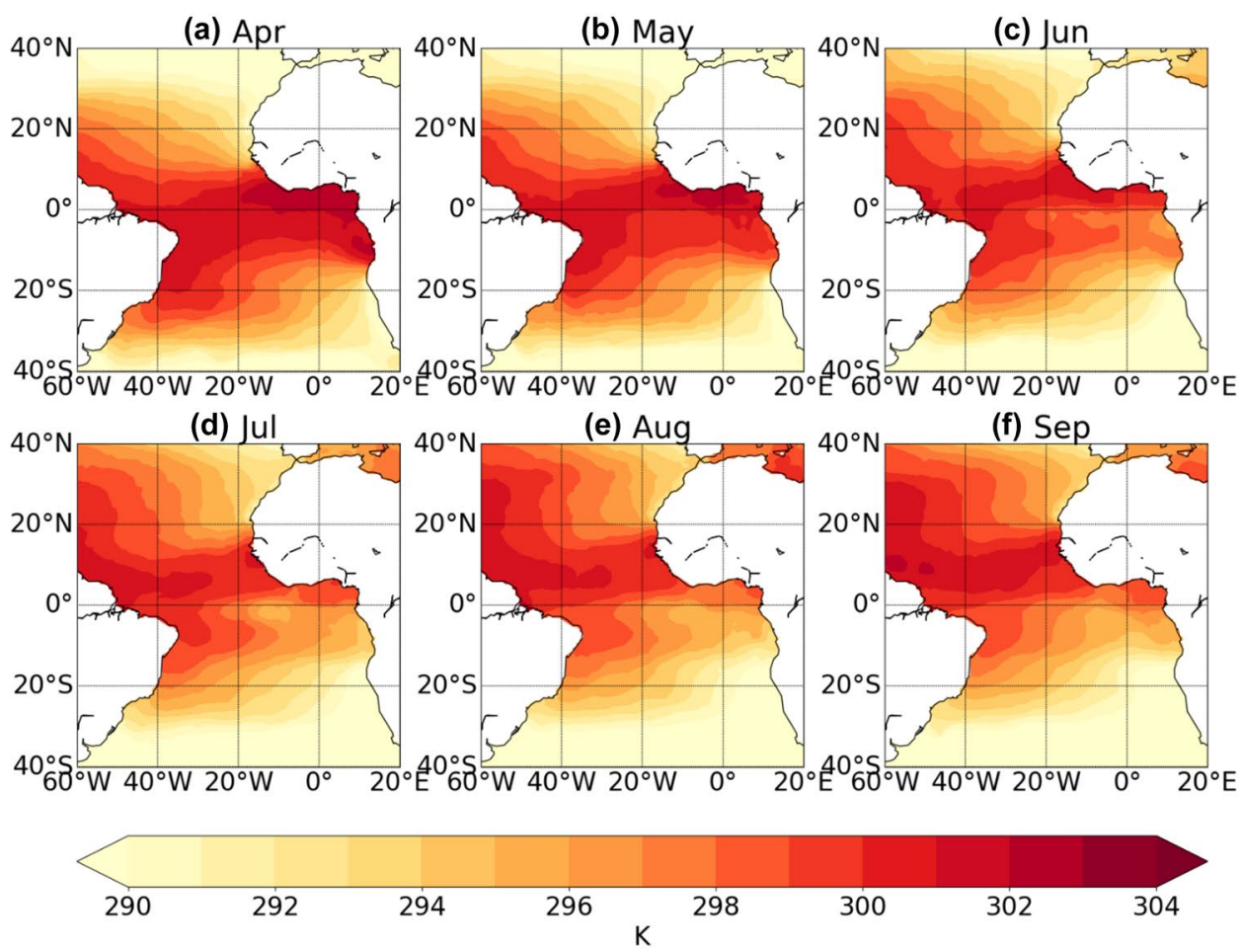

GC2-GC2 minus Observed SST
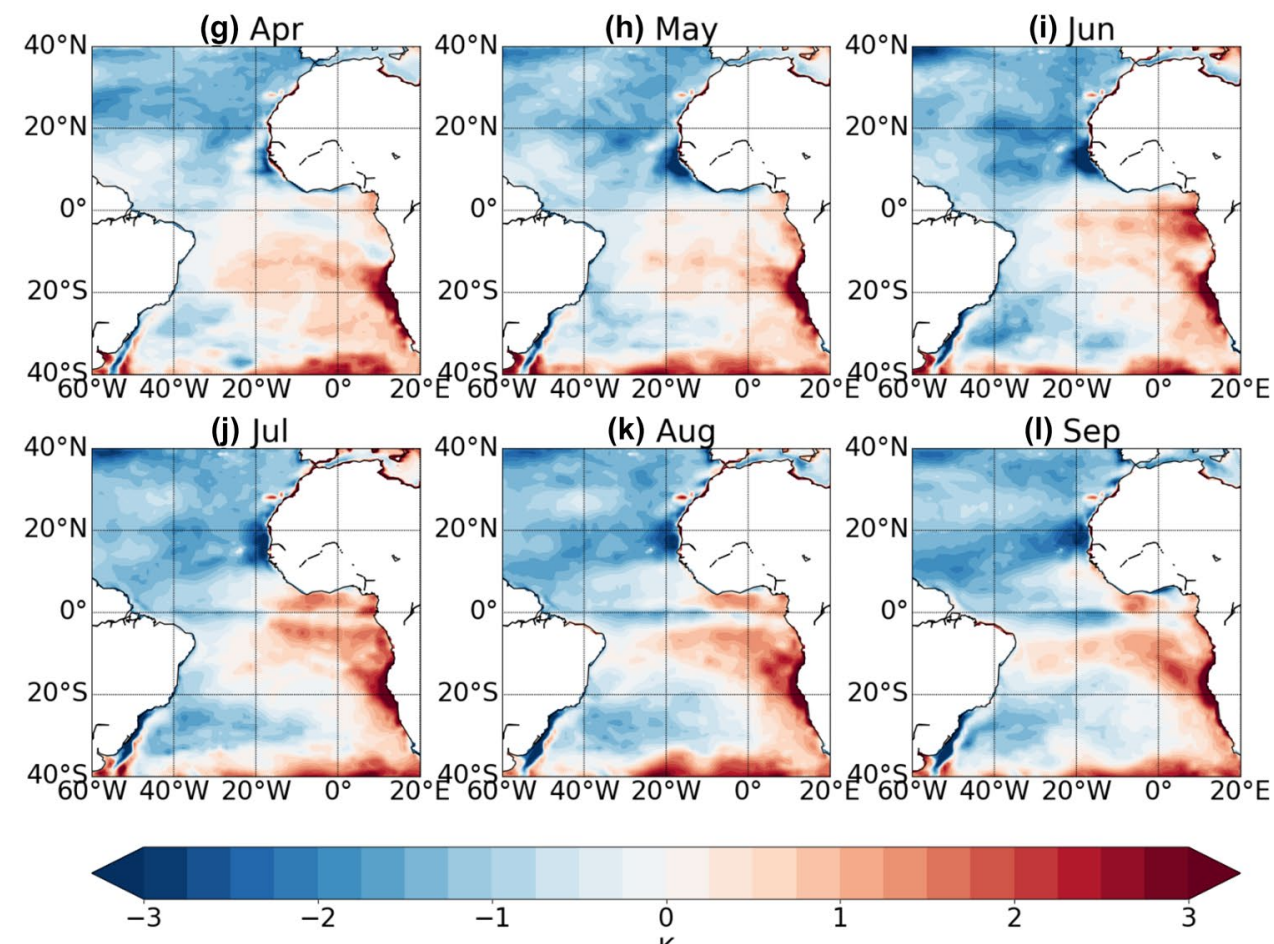

12 of precipitation over the southern part of West Africa and the LDS, via influences on the location of the tropical rain belt and static stability over the coastline. Locally, where warm onshore waters persist (e.g. to the east around the Niger Delta in Nigeria and off the coast of Liberia, e.g. Fig. 1e, f) the LDS is weak or absent (Parker and Diop-Kane 2017). At 
a larger scale, warm biases in tropical South Atlantic SSTs are ubiquitous across the current generation of CGCMs, due to errors in ocean upwelling, marine stratocumulus and equatorial winds (Richter et al. 2012; Găinuşă-Bogdan et al. 2017). Due to the strong relationship between Atlantic SSTs and the West African Monsoon (Hagos and Cook 2009), these biases have been associated with deficiencies in West African Monsoon rainfall (Roehrig et al. 2013). Steinig et al. (2018) and Eichhorn and Bader (2017) found SST biases in the tropical Atlantic were related to precipitation biases over the Guinea coastline. Conversely, several studies including Hagos and Cook (2009) and Okumura and Xie (2004) note the influence of the West African monsoon on SST: weaker winds associated with a deficient monsoon circulation may reduce upwelling and warm SST, reducing the land-sea thermal contrast and thus further reducing the strength of the monsoon circulation. Dunning et al. (2017) found that the Coupled Model Intercomparison Project Phase 5 (CMIP5) historical simulations underestimated SST seasonal cooling from April/May to August over the northern Gulf of Guinea, and proposed that this resulted in the incorrect seasonality of precipitation over the southern coastline of West Africa, and lack of the LDS. However, there are other differences between atmosphere-only and coupled climate model simulations beyond SST that may affect the representation of the LDS, such as the inclusion of air-sea interactions, which has been shown to have significant impacts on the representation of other intra-seasonal tropical phenomena, such as the Madden Julian Oscillation (DeMott et al. 2015).

In this study, we employ the UK Met Office Unified Model (MetUM) to investigate factors influencing the representation of the biannual seasonal cycle of precipitation (including the LDS) over the southern part of West Africa. In addition to standard atmosphere-only and coupled configurations, a novel aspect of the present work involves the application of the Global Ocean Mixed Layer configuration (Hirons et al. 2015). This configuration is a useful research tool for process-based studies. First, it enables us to cleanly identify the role of air-sea coupling on the representation of the LDS. Secondly, it allows us to analyse the impact of different ocean mean states, while maintaining air-sea coupling. The potential mechanisms underlying the representation of the LDS are explored to understand the factors that influence the seasonal cycle over this region. The remainder of the paper is structured as follows; Sect. 2 contains a description of the model simulations, observation data and methods. In Sect. 3 simulations from the atmosphere-only configuration of the MetUM (GA6, Walters et al. 2017) and global coupled model configuration of the MetUM (GC2, Williams et al. 2015) are examined to ascertain whether the MetUM exhibits the same behaviour as the CMIP5 models found in Dunning et al. (2017) and which horizontal resolution is most suitable. In Sect. 4 the impact of air-sea coupling and the ocean mean state on the seasonal cycle of SST over southern West Africa is presented. Section 5 contains the discussion and conclusions.

\section{Model, Methods, Data}

\subsection{MetUM Simulations}

We analyse atmosphere-only and fully coupled simulations from the MetUM Global Atmosphere version 6.0 (GA6, Walters et al. 2017) and MetUM Global Coupled Model version 2.0 (GC2, Williams et al. 2015) respectively. See Table 1 for a full list of simulations used in this study. GA6 is forced using daily observed SST (Reynolds et al. 2007) and sea-ice forcings (Taylor et al. 2012) (including interannual variability) and also includes an interactive land surface. GC2 consists of atmosphere, ocean, sea ice and land surface models, with fluxes of momentum, freshwater and heat exchanged between the atmosphere-land and ocean-ice components via the OASIS3 coupler (Ocean Atmosphere Sea Ice Soil; Valcke et al. 2003) with a 3-h coupling period (Williams et al. 2015). To assess the impact of horizontal

Table 1 List of experiments used in this analysis

\begin{tabular}{lllll}
\hline $\begin{array}{l}\text { Model configura- } \\
\text { tion }\end{array}$ & Ocean reference climatology or SST forcing data & Resolution & No of years ${ }^{\text {a }}$ & Experiment identifier \\
\hline GA6 & SST - Reynolds et al. (2007) & N96, N216 & $26(1983-2008)$ & GA6-OBS \\
& Sea Ice - AMIP & N512 & $9(1982-1990)$ & GC2-GC2 \\
GC2 & - & N96, N216 & 28 & GOML-OBS \\
GOML & Met Office ocean reanalysis (1980-2007) & N96, N216 & 28 & GOML-GC2 \\
GOML & GC2 ocean mean state (100 year average) & N96, N216 & 28 & GOML-ATL-N96 \\
GOML & GC2 ocean mean state (Atlantic) Met Office ocean & N96 & 28 & GA6-GOML \\
GA6 & reanalysis (Indian and Pacific) & N96, N216 & 28 & GML-OBS SST \\
\hline
\end{tabular}

${ }^{a}$ Since the GOML experiments are present-day control simulations with fixed forcing, the simulated years do not correspond to actual years. It is not expected that the GOML simulations match equivalent years in observations. Years are included only for the GA6 simulations 
resolution, we use three GA6 simulations, at N96 $\left(1.88^{\circ}\right.$ longitude $\times 1.25^{\circ}$ latitude $), \mathrm{N} 216\left(0.83^{\circ} \times 0.56^{\circ}\right)$ and N512 $\left(0.35^{\circ} \times 0.23^{\circ}\right)$ horizontal resolution. All simulations have 85 levels in the vertical and a model lid at $85 \mathrm{~km}$. For GC2, the ocean vertical grid has 75 levels, with a $1 \mathrm{~m}$ top level (Williams et al. 2015). For the N96 and N216 resolution GA6 simulations, 26 years of data (1983-2008) are used; for the higher resolution N512 simulation, 9 years (1982-1990) of data are used. For the GC2 simulations, 28 years of data are used; these simulations use present-day (1990) greenhouse gas and aerosol forcing.

We also use the Global Ocean Mixed Layer configuration of the UK Met Office Unified Model (MetUM-GOML). This comprises GA6 coupled to the Multi-Column K-Profile Parametrisation Ocean (MC-KPP) via OASIS3, which consists of a single oceanic column, with high vertical resolution (100 points in $1000 \mathrm{~m}$; top layer $1.2 \mathrm{~m}$ thick) below each atmospheric grid point, with 3-h coupling frequency. To represent the mean ocean advection (including upwelling), and account for biases in the surface fluxes, a seasonal cycle of horizontally- and depth-varying temperature and salinity corrections are applied to constrain the ocean mean state in MetUM-GOML to a reference climatology (e.g. observed ocean state or a coupled model ocean state). The temperature and salinity corrections are computed from a 10-year relaxation simulation using MetUM-GOML, where MCKPP profiles are constrained to the reference climatology with a relaxation timescale of 15 days. The daily mean seasonal cycles of the resulting temperature and salinity tendencies (smoothed with a 31-day running mean) are then applied to a free-running coupled MetUM-GOML simulation with no interactive relaxation. For full details of the simulation design, see Hirons et al. (2015). The structure of MetUM-GOML, with independent one-dimensional ocean columns, and temperature and salinity corrections used to constrain the ocean mean state, means it is very flexible. MetUM-GOML can be constrained to different ocean reference climatologies, regionally or globally, by changing the corrections applied, and independent ocean columns mean that both corrections and air-sea coupling can be applied selectively in time and space. Furthermore, the lack of threedimensional ocean dynamics means MetUM-GOML is computationally inexpensive (Hirons et al. 2015).

We use three sets of MetUM-GOML simulations (Table 1). The first set of simulations uses the observed ocean mean state from the Met Office ocean analysis (Smith and Murphy 2007) as the reference climatology. The second uses the ocean mean state from the GC2 simulations as the reference climatology. These simulations were performed at N96 and N216 horizontal resolutions. For the third simulation, the reference climatology is a hybrid of observations and GC2. The GC2 ocean mean state is used over the Atlantic Basin $\left(67^{\circ} \mathrm{W}-23^{\circ} \mathrm{E}\right.$, with the latitudinal extent determined by the maximum extent of seasonally varying sea ice; see Fig. 2 in Hirons et al. 2015), while the observed ocean mean state is used outside the Atlantic. Each experiment is named using the model configuration used, the reference ocean climatology, and the horizontal resolution, thus the MetUM-GOML configuration constrained to the GC2 ocean mean state at N96 resolution is labelled 'GOML-GC2-N96'. 28-year simulations are analysed, with present-day greenhouse gas and aerosol forcing.

Using GOML enables us to cleanly separate the role of air-sea interactions and the role of mean-state ocean biases on the representation of the seasonal cycle of precipitation over the southern part of West Africa, within a coupled framework. Table 2 summarises the comparisons used in this study. Hirons et al. (2015) demonstrate that when MetUMGOML is constrained to observations, the SST biases are small (also seen in Fig. 2b); thus by analysing GOML-OBS the role of air-sea interactions can be examined in a model with a more accurate ocean mean state than GC2. However, Fig. $2 b$ shows that the inclusion of air sea coupling in GOML-OBS does result in some small SST biases. We performed a further GA6 simulation (GA6-GOML), forced with 31-day smoothed SSTs (including interannual variability) from GOML-OBS to isolate the role of air-sea interactions, with identical mean SST.

Comparing GOML-OBS with GOML-GC2 explores the role of ocean mean state biases, while maintaining coupling and using the same model configuration. Figure 2a, c demonstrates that GOML-GC2 replicates the mean SST biases from $\mathrm{GC} 2-\mathrm{GC} 2$.

Finally, by comparing GOML-ATL-N96 to GOML-OBS and GOML-GC2, it is possible to ascertain whether the differences between GOML-OBS and GOML-GC2 are associated with mean ocean biases in the Atlantic Ocean, or mean ocean biases in the Pacific and Indian Oceans. Mohino et al. (2011) identified interactions between the Pacific and Indian Oceans and the West African monsoon and rainfall over the Gulf of Guinea, which suggests that biases in the Pacific and Indian Oceans may affect the LDS. Figure $2 d$ shows the difference in annual mean SST between GOML-ATL-N96 and observed SST. Over the south-east Tropical Atlantic a warm bias is apparent, which is present in GC2 (Fig. 2a, c)

Table 2 Experiment comparisons used in this study, and the impacts revealed

\begin{tabular}{ll}
\hline Comparison & Impact of \\
\hline GOML-OBS vs GA6-GOML & Air sea coupling \\
GOML-GC2 vs GOML-OBS & Ocean mean state (Global) \\
GOML-ATL-N96 vs GOML-GC2-N96 & Ocean mean state (Atlantic) \\
GOML-ATL-N96 vs GOML-GC2- & Ocean mean state (Atlantic) \\
N216 & and horizontal resolution \\
\hline
\end{tabular}


(a) GC2-GC2 minus Observed SST

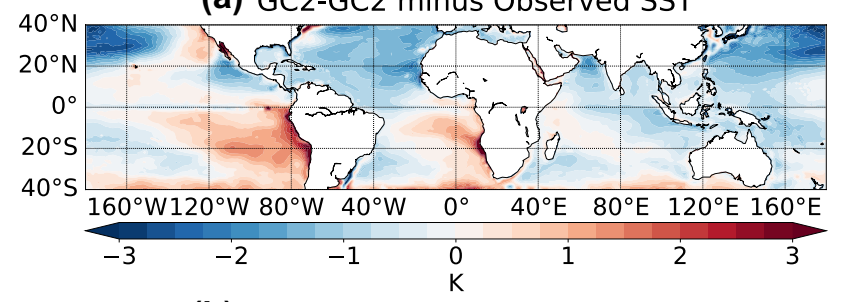

(b) GOML-OBS minus Observed SST

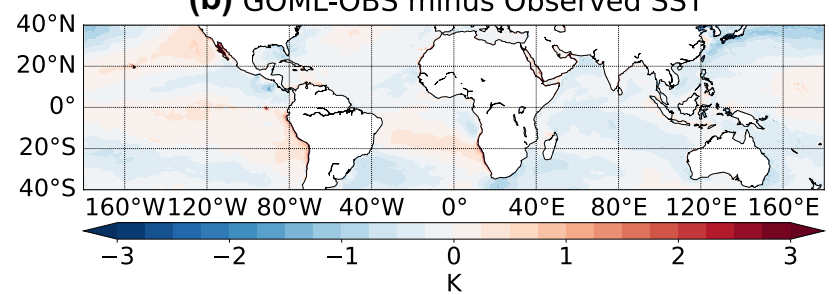

(c) GOML-GC2 minus Observed SST

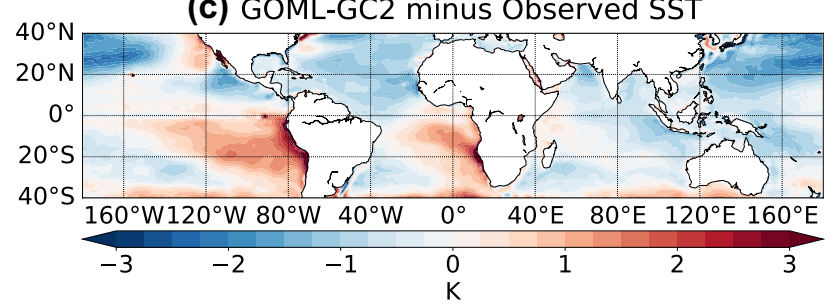

(d) GOML-ATL-N96 minus Observed SST

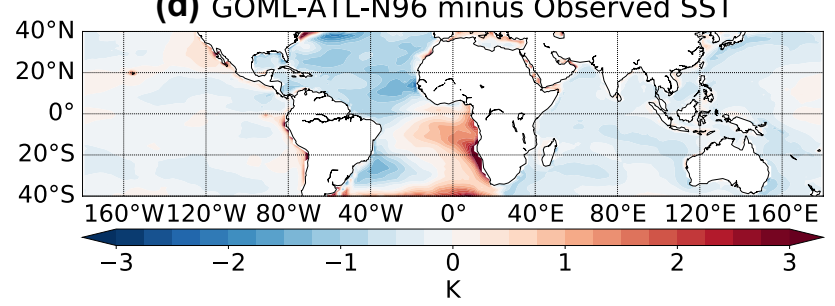

Fig. 2 Difference between observed SST (Smith and Murphy 2007) and annual mean surface temperature from a GC2-GC2, b GOMLOBS, c GOML-GC2, at N216 resolution and $\mathbf{d}$ GOML with observed ocean (Indian and Pacific) and GC2 ocean mean state over the Atlantic (GOML-ATL-N96), at N96 resolution

and the majority of coupled climate models (Richter et al. 2012; Eichhorn and Bader 2017; Steinig et al. 2018). Over the Indian and Pacific basins the differences in surface temperature are smaller, similar to Fig. $2 b$.

\subsection{Observations}

The Global Precipitation Climatology Project (GPCP) 1-Degree Daily precipitation dataset combines thermal infrared and passive microwave satellite data with rain gauge data to produce daily rainfall estimates over both land and ocean (Huffman et al. 2001). GPCP data for 1997-2014 were used on the native $1^{\circ} \times 1^{\circ}$ grid.

For horizontal wind and mean vertical velocity, ERAInterim (ERA-I) reanalysis data were used over 1983-2010. ERA-I is produced using the European Centre for Medium Range Weather Forecasts' (ECMWF) Integrated Forecast
System combined with data assimilation for the global atmosphere at $0.75^{\circ}$ resolution (Dee et al. 2011). Six-hourly eastward (u), northward (v) and vertical (omega) winds were averaged to produce monthly means. For Fig. 9, 12-hourly total precipitation was averaged to produce monthly means.

Observed SSTs were obtained from Met Office ocean analysis (Smith and Murphy 2007), at both N216 and N96 resolution, averaged over 1980-2009.

\subsection{Methods}

The region that experiences the LDS (Fig. 4a, dark blue crosses) was defined as follows. Firstly, only land grid points within $20^{\circ} \mathrm{W}-10^{\circ} \mathrm{E}, 0^{\circ}-15^{\circ} \mathrm{N}$ were considered, to isolate the correct part of West Africa (dashed box in Fig. 4a). Secondly, each grid point within this region was categorised as either 'annual' (one wet season, no LDS) or 'biannual' (two wet seasons). As in Liebmann et al. (2012) and Dunning et al. (2016), harmonic analysis was used to categorise the seasonal regime at each grid point as either annual or biannual. The amplitude of the first and second harmonics at each grid point are computed using daily rainfall, and the ratio is calculated. If the amplitude of the second harmonic is greater than the first (ratio $>1.0$ ), then the gridpoint experiences a biannual regime, whereas if the amplitude of the first harmonic is greater (ratio $<1.0)$ then the gridpoint experiences an annual seasonal regime. Only the biannual points (within $20^{\circ} \mathrm{W}-10^{\circ} \mathrm{E}$, $0^{\circ}-15^{\circ} \mathrm{N}$ ) comprise the Little Dry Season region (Fig. 4a, dark blue crosses). This region is in good agreement with that used in other studies of the LDS (Odekunle and Eludoyin 2008).

The same methodology, of calculating the harmonic ratio, is used in Fig. 5 to identify regions with annual or biannual seasonal regimes.

In Sect. 4 the mean monthly position and width of the Tropical Rain Belt (TRB) is compared across the simulations, and with observations. The monthly mean location of the TRB is defined using a method for identifying the location of the Inter-Tropical Convergence Zone (ITCZ; Shonk et al. 2018). Mean monthly rainfall is computed for each month at each grid point over $30^{\circ} \mathrm{S}-30^{\circ} \mathrm{N}$. For each month and longitude, the latitude of the rainfall centroid is computed, using only latitudes where the rainfall is above half the maximum rainfall rate. The latitude of the rainfall centroid is taken to be mean latitudinal position of the TRB. The width of the TRB was defined using a $3 \mathrm{~mm} /$ day threshold either side of the mean latitude.

\section{Performance of MetUM and the role of horizontal resolution}

Figure 3 shows the seasonal rainfall and $10 \mathrm{~m}$ winds. The seasonal meridional progression of the main tropical rain belt is apparent, with the rain belt positioned over the 
northern Gulf of Guinea and southern part of West Africa in boreal spring and autumn, and travelling further north over the Sahel in boreal summer. The south-westerly monsoon winds and north-easterly Harmattan winds are also apparent.

We first assess whether the MetUM exhibits the same behaviour as other CMIP atmosphere-only and coupled simulations, as found in Dunning et al. (2017): specifically whether GA6 captures the correct seasonal cycle including the Little Dry Season and whether GC2 contains one season per year, with the peak in July-August. We also investigate which horizontal resolution is most suitable for this analysis, based on representation of the mean seasonal cycle over southern West Africa.

GA6-OBS correctly captures the first wet season and the Little Dry Season (LDS) at all resolutions (Fig. 4). However, the magnitude of the second season is much lower than observed, particularly in the N96 simulation. GC2-GC2 contains one wet season per year, with the peak of the wet season in July-August, in agreement with the coupled simulations from CMIP5 (Dunning et al. 2017). Thus the MetUM can be used to investigate this discrepancy further.

Rainfall bias maps for June-August (JJA) and September-November (SON, see Supplementary Information) show that while GA6-OBS and GC2-GC2 produce rainfall across West Africa in JJA, moving south in SON, they exhibit a dry bias over the Sahel in JJA and over West Africa south of $15^{\circ} \mathrm{N}$ in SON. The JJA bias has also been identified in other studies (Williams et al. 2015; Walters et al. 2017). Thus this suggests that the underestimation of the second wet season in Fig. 4 indicates wider scale biases in the representation of
Fig. 3 Seasonal mean rainfall (GPCP) and 10m winds (ERA-I)

Fig. 4 Crosses in a indicate the region that experiences the LDS (see Sect. 2.3 for definition). Panel b shows the mean annual cycle of precipitation over the LDS region (shown in panel a) in GA6-OBS at N96, N216 and N512 resolution and GC2-GC2 at $\mathrm{N} 96$ and $\mathrm{N} 216$ resolution. For the time periods used see Table 1. The black solid line shows the mean seasonal cycle from GPCP over 1997-2014
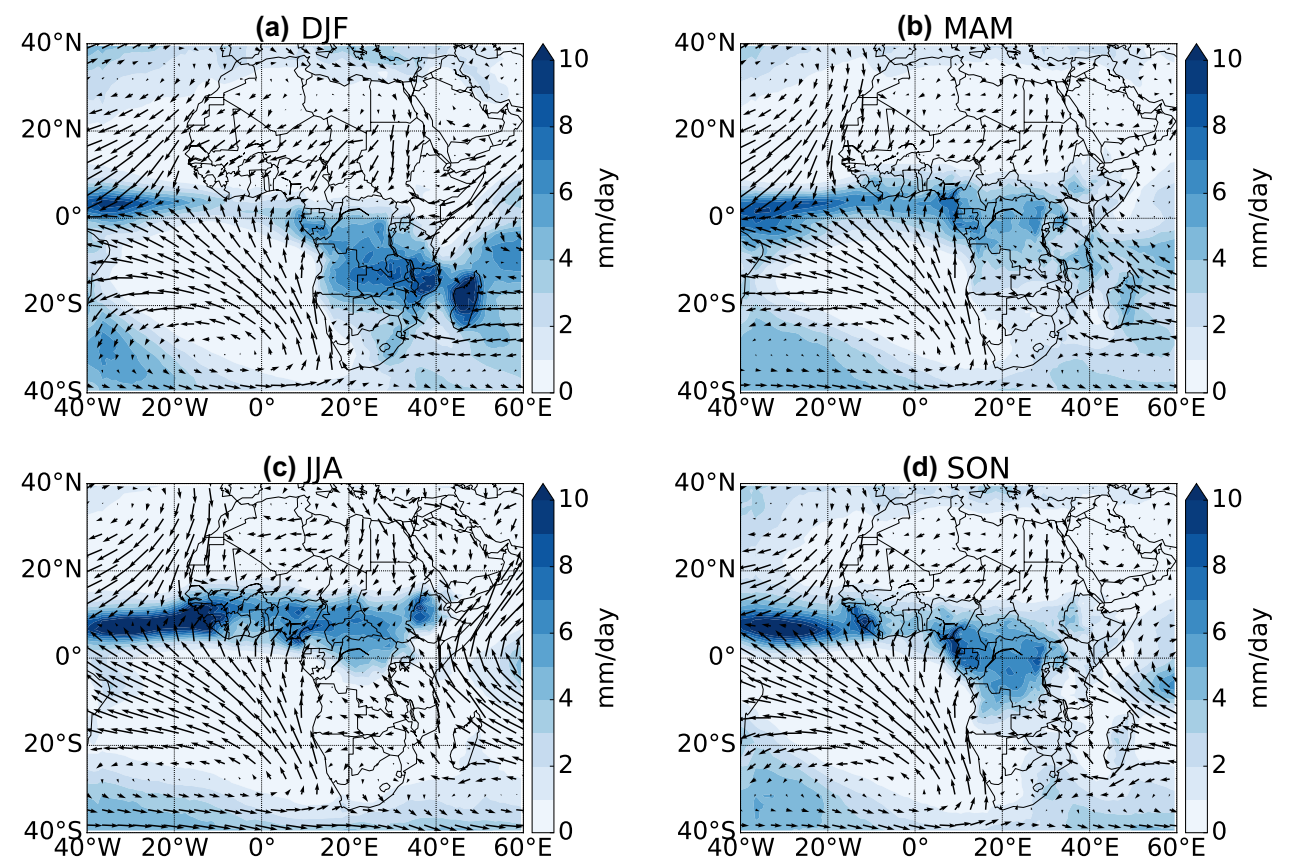

(b) Mean Annual Cycle over LDS Region
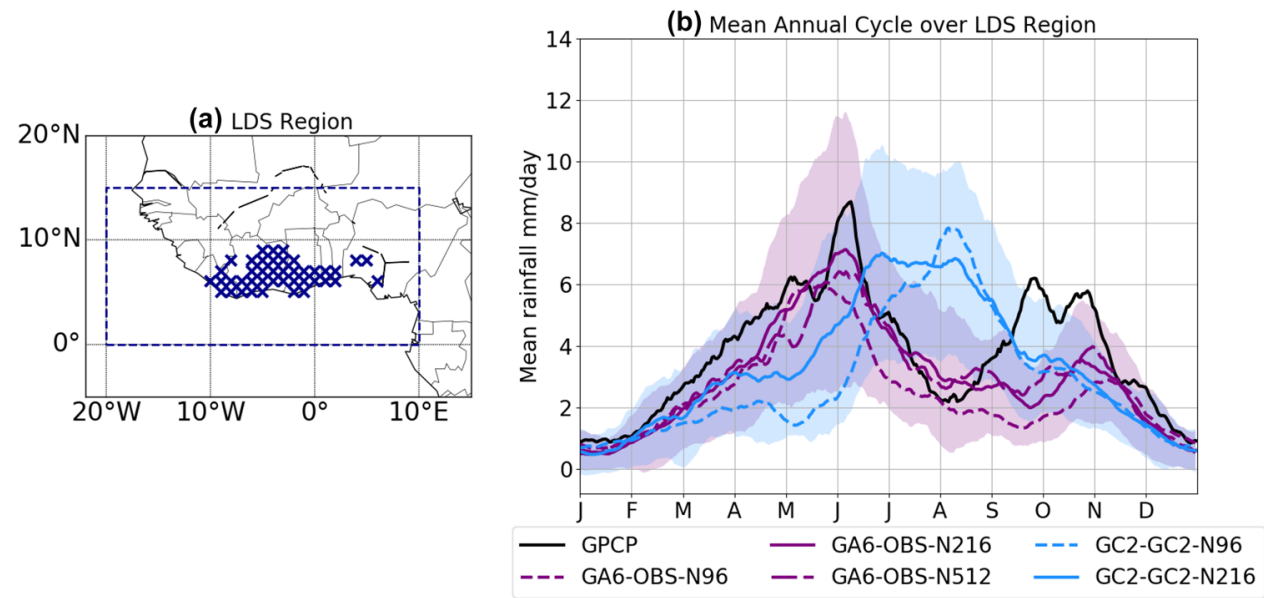
(a) GA6-OBS-N96

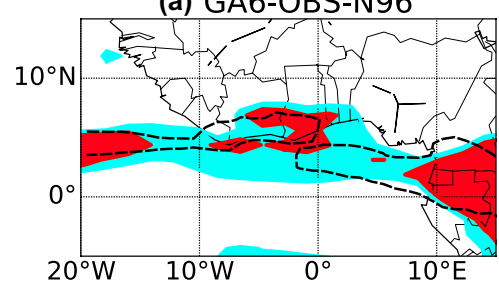

(d) GC2-GC2-N96

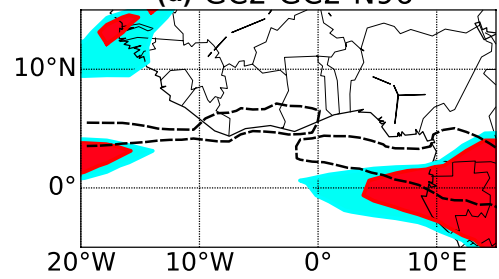

(b) GA6-OBS-N216

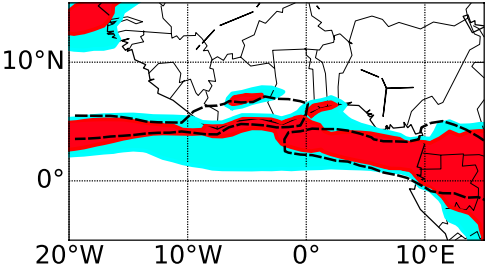

(e) GC2-GC2-N216

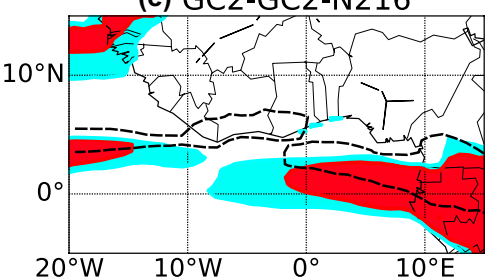

(c) GA6-OBS-N512

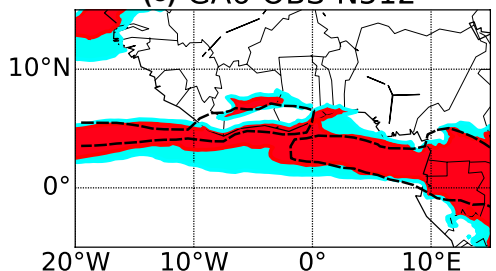

$\begin{array}{llll}- & >1.0 & --- & \text { GPCP } \\ & >0.75\end{array}$
Fig. 5 Ratio of the amplitude of the second harmonic to the amplitude of the first harmonic at each grid point across West Africa for 3 GA6-OBS simulations at N96 (1983-2008), N216 (1983-2008) and N512 (1982-1990) resolutions and 2 GC2-GC2 simulations at N96 and N216 resolution (28 years). In general, a high ratio (greater than

the monsoon, in atmosphere-only and coupled simulations. In particular, the presence of a dry bias in SON, without a neighbouring wet bias, suggests that this error is related to rainfall amplitude, not a spatial displacement. Stratton et al. (2018) found that at convection-permitting resolution the MetUM showed smaller JJA rainfall biases, due to a better representation of westward propagating mesoscale convective systems and more rainfall at higher rain rates. In this study the focus is on the differences between atmosphereonly and coupled simulations and impacts upon the southern part of West Africa, hence the factors leading to the underestimation of the second wet season are not explored further.

Horizontal resolution improves the representation of the seasonal cycle in the LDS region from N96 to N216 (Fig. 4). The rainfall maxima are higher at N216, closer to the GPCP rainfall totals. None of the simulations correctly capture the magnitude of the second wet season. N512 resolution shows little benefit over N216.

Figure 5 shows the region that experiences a biannual regime in the GA6-OBS and GC2-GC2 simulations (red), defined using harmonic analysis (ratio threshold of 1.0, see Sect. 2.3), at different resolutions, compared with GPCP (black dashed line). Liebmann et al. (2012) use a threshold of 0.75 to maximise the region with a biannual regime, hence regions where the ratio is greater than 0.75 are marked in blue. White indicates an annual regime (ratio less than 0.75). Both the GA6-OBS N216 and N512 simulations contain a zonal band that experiences a biannual regime, similar to that found in GPCP. In the N96 simulation this band is split, with a biannual seasonal regime at only a few longitudes. For GC2 the band is split at N96 and N216 resolution, with a biannual regime not captured between $10^{\circ} \mathrm{W}$ and
1.0) indicates a biannual seasonal cycle, while a low ratio (less than 1.0) indicates an annual seasonal cycle. The black contour shows the location where the ratio is equal to 1.0 when GPCP data is used, therefore demarcating the region that experiences a biannual regime. White indicates the ratio is less than 0.75 (annual regime)

$0^{\circ}$. Figure 5 suggests that the N216 simulation captures the seasonal cycle better than the N96 simulation, but the difference between N216 and N512 is minimal. Vellinga et al. (2016) found that higher resolution MetUM simulations capture the westward propagating, intense convection systems over West Africa that bring much of the seasonal rainfall, while in lower resolution simulations rainfall is weaker and occurs synchronously across the Sahel. Additionally, using higher resolution enables the model physics to better represent the processes and interactions between rainfall and dynamics, leading to more realistic representation of strong rainfall events and decadal trends (Vellinga et al. 2016), although they also found greatest benefit at N512, not N216. Throughout the remainder of this study N216 resolution is used (except for GOML-ATL-N96).

\section{Effect of air-sea interactions and Ocean mean state on the LDS}

\subsection{Impact of air-sea coupling}

Comparing GA6-GOML and GOML-OBS (and GA6OBS) cleanly identifies the impact of air-sea coupling (see Sect. 2.1, Table 2), analysis that is made possible by using the MetUM-GOML configuration. The seasonal cycle of precipitation over the LDS region (Fig. 4a) from these three simulations is shown in Fig. 6a. All three simulations show similar seasonal cycles that agree with GPCP from JanuaryAugust and December, but underestimate the second wet season during September-November. The correlation matrix in Fig. $6 \mathrm{~b}$ shows strong correlations, with coefficients greater 
than 0.9 , between the three seasonal cycles, and statistically significant positive correlations with GPCP, with coefficients greater than 0.81 . Some slight differences between GA6-OBS and GA6-GOML (Fig. 6) suggest that small SST biases in GOML-OBS influence the precipitation seasonal cycle here. Including air-sea coupling, while maintaining the same mean SST, has a minimal impact on the representation of the seasonal cycle over the LDS region and does not improve the intensity of the second wet season.

\subsection{Impact of ocean mean states}

Comparing GOML-GC2 to GOML-OBS isolates the effect of the ocean mean states on the seasonal cycle of precipitation over the southern part of West Africa (see Sect. 2.1, Table 2). Both GC2-GC2 and GOML-GC2 misrepresent the seasonal cycle, with one wet season per year, with the peak in rainfall occurring when the LDS should occur (Fig. 6a), hence the inclusion of coupled model ocean mean state biases leads to the incorrect seasonal cycle. Figure 6a shows that the difference between GOML-GC2 and GOML-OBS is much greater than the difference between GOML-OBS and GA6-OBS, indicating that GC2 ocean mean state biases have a bigger impact on the seasonal cycle of precipitation in the LDS region than the inclusion of air-sea coupled physics.

The seasonal cycle from GOML-ATL-N96 (Fig. 6a) shows similar patterns to GOML-GC2, with one wet season per year, peaking in July/August, during the observed LDS. GOML-ATL-N96 underestimates rainfall relative to GOML-GC2-N216, but has similar rainfall totals with GOML-GC2-N96 (Fig. 6a), suggesting this underestimate is related to horizontal resolution rather than differences in the ocean mean state.

The correlation of the mean annual rainfall cycle across the simulations (Fig. 6b) demonstrates greatest agreement between the simulations with the same ocean mean state (e.g. between GA6-OBS and GOML-OBS, and between GC2-GC2 and GOML-GC2). Conversely, agreement is much lower between simulations with the same model and resolution but different ocean states (e.g. GOML-OBS and GOML-GC2). Figure $6 \mathrm{~b}$ indicates better agreement between GOML-ATL-N96 and either GOML-GC2-N96 or GOML-GC2-N216 (correlation coefficients of 0.974 and 0.931 respectively), than between GOML-ATL-N96 and GOML-OBS (correlation coefficient of 0.304). Thus we surmise that the incorrect representation of the seasonal cycle of rainfall over the southern part of West Africa in GOML$\mathrm{GC} 2$ is related to GC2 Atlantic Ocean mean state biases.

The incorrect seasonal cycle for simulations with coupled model ocean mean state in the Atlantic (GC2-GC2, GOMLGC2 and GOML-ATL-N96, Fig. 6a) can be partitioned into a number of components: a late onset and deficient rainfall in May; excess rainfall in July-August, during the peak of the LDS; and insufficient rainfall in October (seen in all simulations). The first two factors, which are not exhibited in GA6-OBS and GOML-OBS, will be explored further.

To compare the location of the rainfall among simulations, Fig. 7 shows the mean monthly position of the TRB (Sect. 2.3), in May and August. As in Fig. 6, the GOML simulations are similar to the GA6 and GC2 simulations with the same ocean mean state; GOML-ATL-N96 is similar to GOML-GC2 and GC2-GC2. In May and August

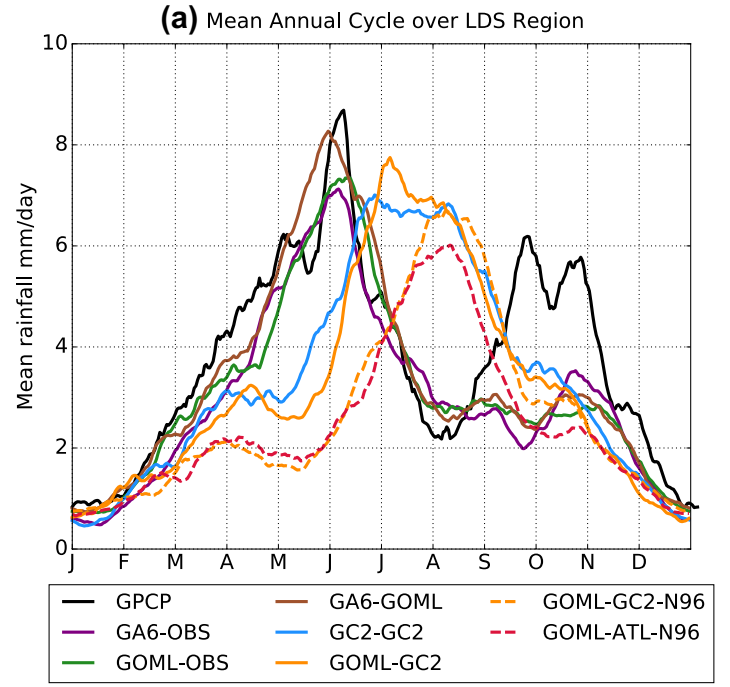

Fig. 6 a Mean annual cycle of precipitation over the LDS region (Fig. 4a) using the simulations listed in Table 1. The black solid line shows the mean seasonal cycle from GPCP over 1997-2014. b Pear- (b) Correlation of seasonal cycle over LDS region

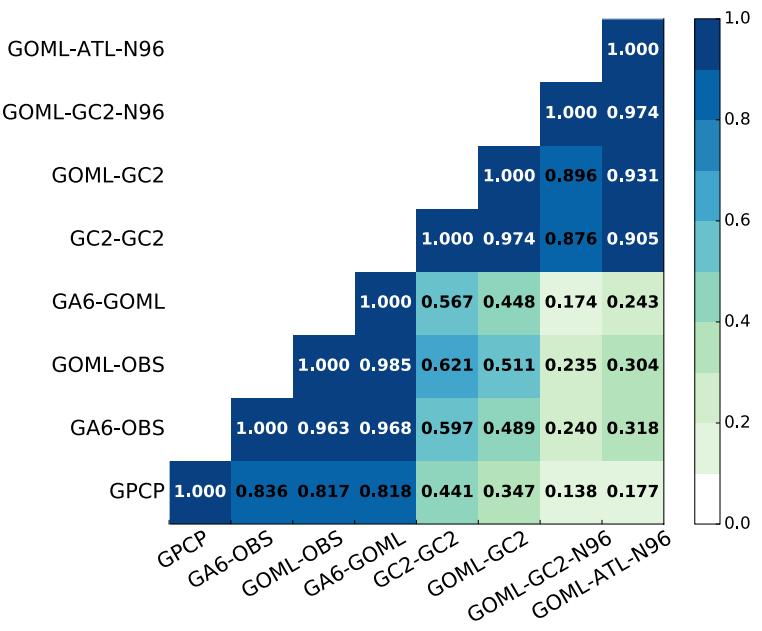

son correlation coefficients between the mean seasonal cycle over the LDS region from each pair of simulations 
all simulations place the TRB south of the observed position in GPCP, especially in those simulations with GC2 ocean state in the Atlantic (GC2-GC2, GOML-GC2 and GOML-ATL-N96).

In May, the TRB is just south of the coastline in GPCP (Fig. 7a). The TRB in GA6-OBS and GOML-OBS is just south of the GPCP mean position (Fig. 7a), but in GC2-GC2, GOML-GC2 and GOML-ATL-N96 the TRB is further south, just north of the equator. The northern and southern limits (solid and dashed lines respectively; Fig. 7c) confirm this southward bias; the TRB is over approximately $0^{\circ} \mathrm{N}-10^{\circ} \mathrm{N}$ in GPCP, GA6-OBS, and GOML-OBS, but over approximately $5^{\circ} \mathrm{S}$ to the coastline in GC2-GC2, GOMLGC2 and GOML-ATL-N96, consistent with the lower rainfall in May over the southern part of West Africa (Fig. 6). Previous studies suggest that the southward bias in mean TRB position is related to warm SST biases in the Gulf of Guinea (Fig. 1, Roehrig et al. 2013), which will be discussed in more detail in Sect. 4.3. Consistent results across GOMLGC2 and GOML-ATL-N96 confirm this bias is related to Atlantic Ocean mean state SST errors.

In August, the TRB is over Burkina Faso in GPCP, while GA6-OBS and GOML-OBS exhibit a southward shift, with the TRB over northern Ghana and Ivory Coast (Fig. 7b). Again, GC2-GC2 and GOML-GC2 place the TRB even further south, with GOML-ATL-N96 exhibiting an additional southward bias (Fig. 7b). The position of the northern boundary is the same in four simulations (GA6-OBS, GC2-GC2, GOML-OBS and GOML-GC2), passing through Senegal, Southern Mali and along the southern boundary of Niger (Fig. 7d). The key difference between these simulations is related to the position of the southern boundary, which leads to the differences in mean position (Fig. 7b). In GPCP, GA6-OBS, and GOML-OBS the southern part of the Ivory Coast and Ghana are outside the southern limit of the TRB in August, consistent with the low rainfall in August

\section{Mean Tropical Rain Belt Position}
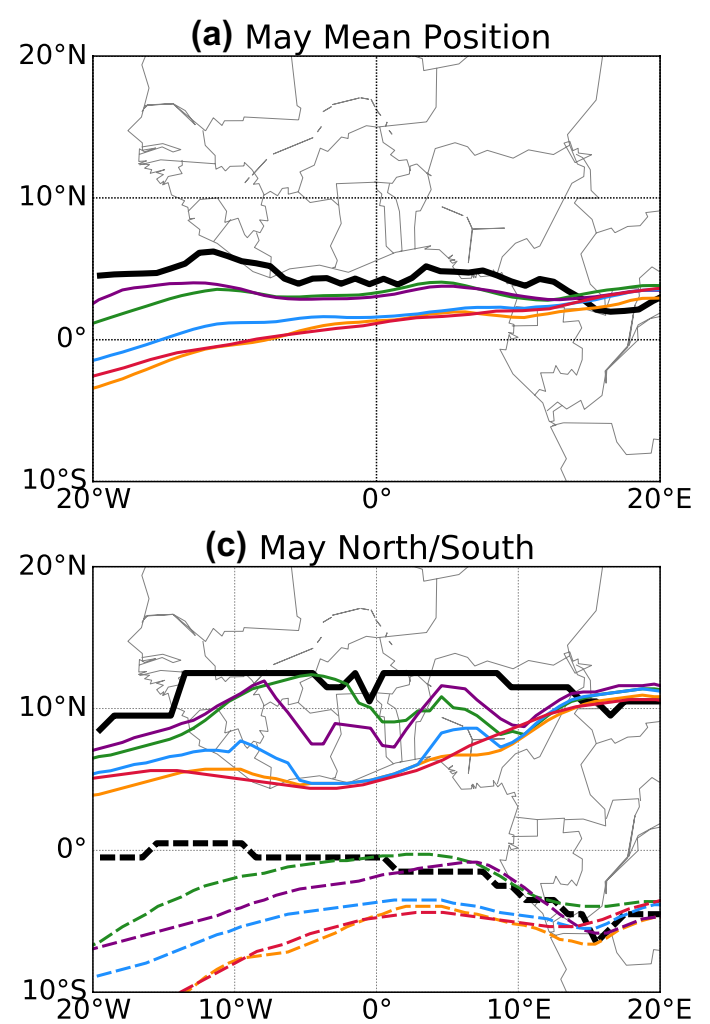

(b) August Mean Position

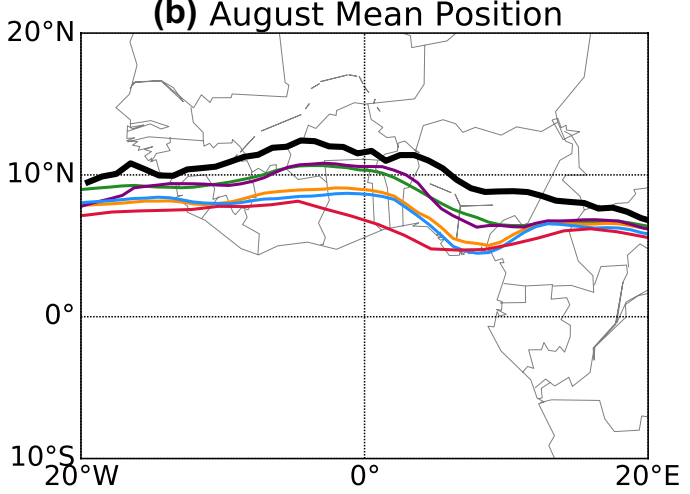

(d) August North/South

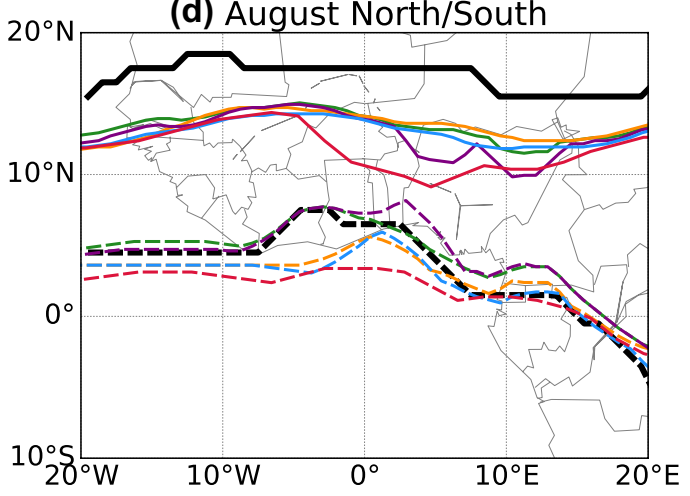

\begin{tabular}{lllll|}
- GPCP & - & GOML-GC2 & - & GC2-GC2 \\
- GOML-OBS & - & GA6-OBS & - & GOML-ATL-N96 \\
\hline
\end{tabular}

Fig. 7 Mean monthly position of the Tropical Rain Belt (a, b) and mean position of the northern and southern limits of the Tropical Rain Belt (c, d) for May and August. The mean monthly position is calculated by identifying the rainfall centroid using the top $50 \%$ of rainfall at each longitude $(\mathbf{a}, \mathbf{b})$. The northern and southern limits are defined using a threshold of $3 \mathrm{~mm} /$ day. Different coloured lines are for different simulations. Details of dates and simulations are depicted in Table 1 
(Fig. 6a) and the correct representation of the LDS. In GC2-GC2, GOML-GC2 and GOML-ATL-N96 the southern limit of the TRB is south of the coastline between $20^{\circ} \mathrm{W}$ and $10^{\circ} \mathrm{E}$, consistent with the high rainfall over the southern part of West Africa and the incorrect representation of the LDS. The different positions of the southern boundary over the LDS region $\left(10^{\circ} \mathrm{W}-2^{\circ} \mathrm{E}\right)$ can clearly be seen in Fig. $7 \mathrm{~d}$. This indicates that the incorrect representation of the LDS in simulations with GC2 SST biases is not solely related to an overall southward shift of the TRB, but may also be related to more local factors (see Sect. 4.4), including differences in regional patterns of ascent and descent. GOML-ATL-N96 exhibits a southward shift in both the northern and southern boundaries, which is related to horizontal resolution; see Supplementary Information for Fig. 7 replicated at N96 (Fig. S3).

In the next sections May and August are considered separately, and factors related to the rainfall biases in these months are presented. In Sect. 4.3 the southward bias in the TRB position in May, and associated patterns of wind and SST biases are discussed, while in Sect. 4.4 the rainfall overestimate in August is explored together with the patterns of ascent and descent along the coastline.

\subsection{Southward Bias in the TRB position in May}

In May, simulations using coupled model ocean mean state (GC2-GC2, GOML-GC2, and GOML-ATL-N96), which includes a warm bias over the southern tropical Atlantic, underestimate rainfall over the LDS region (Fig. 6a) as part of a wider southward bias in the position of the tropical rain belt (Fig. 7a, c).

A number of studies have identified a southward bias in the ITCZ in CGCMs, and associated this with SST biases over the tropical Atlantic (Richter and Xie 2008; Richter et al. 2012; Roehrig et al. 2013; Toniazzo and Woolnough 2014). Coupled climate models, including GC2 (Fig. 2), exhibit a large warm bias in the south east tropical Atlantic, peaking at the Angola/Namibia coastline and extending north-west towards the equator, covering much of the basin (Eichhorn and Bader 2017). Furthermore, coupled climate models fail to capture the equatorial cold tongue that forms in the eastern equatorial Atlantic during boreal summer (Fig. 1); combined with the cold bias to the west, this reverses the equatorial zonal SST gradient (Richter et al. 2012). SST sensitivity experiments have shown that improved representation of Atlantic SSTs (Eichhorn and Bader 2017), and in particular the Atlantic cold tongue, improves the onset and seasonal evolution of the West African monsoon (Steinig et al. 2018), as colder SSTs in the cold tongue enhance the land-sea temperature contrast and strengthen the monsoon flow (Okumura and Xie 2004; Chang et al. 2008).
GOML-GC2 and GOML-ATL-N96 show a cold SST bias north of the equator and warm bias south of the equator in May (Figs 1,8), which likely contributes to the southward bias in the position of the TRB by altering the interhemispheric temperature gradient. A warmer Southern Hemisphere (and cooler Northern Hemisphere) is associated with a northward cross-equatorial atmospheric energy transport and a southward displacement of the tropical rain belt (Hwang and Frierson 2013; Hawcroft et al. 2017).

ERA-I and observed SST (Smith and Murphy 2007) exhibit a northwest-southeast temperature gradient across the tropical Atlantic, with south-easterly winds from the cooler waters off the Angola/Namibia coastline towards the warmer western equatorial Atlantic (Fig. 8a). The same pattern is found in GOML-OBS, with small biases (Fig. 8b). GOML-GC2 and GOML-ATL-N96 (Fig. 8c, d) contain a simpler north-south temperature gradient in the equatorial region, demonstrated by the warm bias in the east and cool in the west, with associated northwesterly wind anomalies between $0^{\circ} \mathrm{S}$ and $5^{\circ} \mathrm{S}$. These wind biases are also likely to be linked to the southward shift of the TRB. Although the investigation of the relationship between biases in Atlantic SST, wind and precipitation has been the focus of many studies (Okumura and Xie 2004; Richter and Xie 2008; Richter et al. 2012, 2014), establishing causal mechanisms remains a challenge, as in other basins (Shonk et al. 2018).

Richter and Xie (2008) and Richter et al. (2012) argue that the westerly bias in surface winds over the equatorial Atlantic during boreal spring, also present in atmosphereonly simulations, causes equatorial Atlantic SST biases. Weakened easterlies are associated with a deeper thermocline in the east and reduced equatorial upwelling, which inhibits equatorial cold tongue formation. Similarly, Fig. $8 \mathrm{~b}$ shows small north-westerly wind biases in the western equatorial Atlantic in May. Voldoire et al. (2019) found that imposing the correct wind stress over the equatorial Atlantic reduces biases in SST and equatorial thermocline depth. The eastern warming and western cooling in turn induces westerly wind biases via a Bjerknes feedback mechanism (Richter and Xie 2008). Richter et al. (2012) propose that this westerly wind bias originates from excess convection over tropical Africa and reduced convection over South America, which initiates a pressure gradient that drives the westerly wind anomalies (Richter and Xie 2008). In addition, Richter et al. (2014) highlighted the role of latitudinal position of the boreal spring ITCZ on equatorial surface winds, with a southward shift of the ITCZ linked to the westerly wind bias at the surface. The same pattern of biases is seen in Fig. 8 (and Fig. 7), which may suggest that the same processes and feedbacks are active in GOML-GC2 (and GOML-ATLN96). Additionally, other studies have noted the role of the West African monsoon winds on SST, as the cross-equatorial southerlies induce Ekman upwelling south of the equator 
(a)

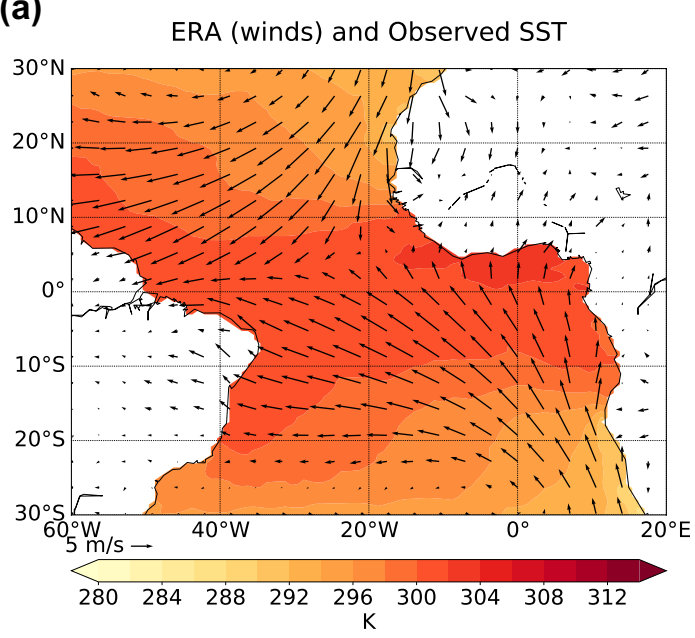

(c)

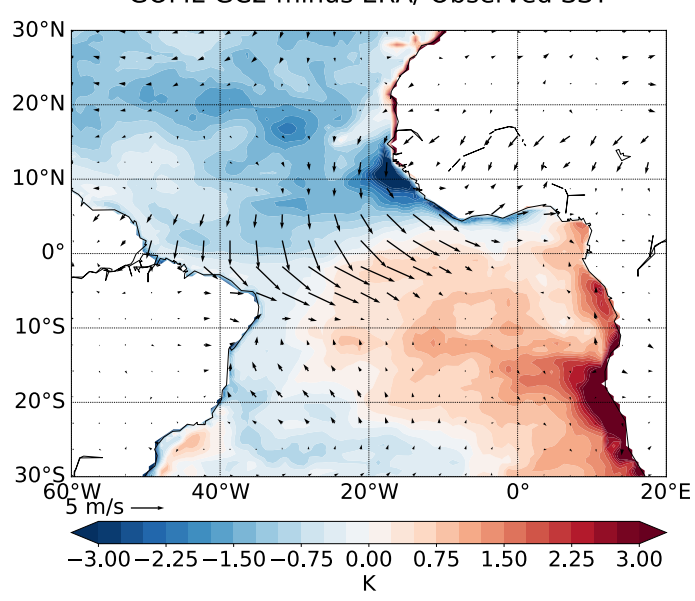

(e)

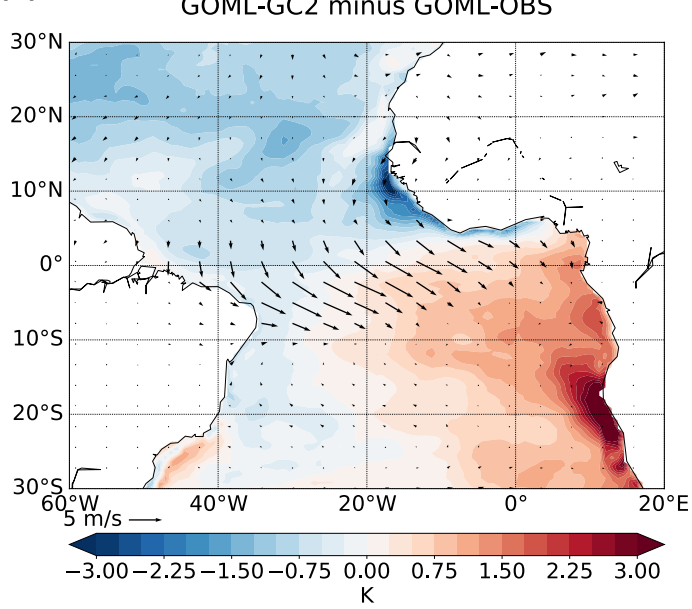

Fig. 8 Mean $10 \mathrm{~m}$ wind (vectors) and surface temperature (coloured contours) in May in a ERA/Observed SST (Smith and Murphy 2007) (winds/surface temperature respectively). Difference between ERA-I (b)

GOML-OBS minus ERA/ Observed SST

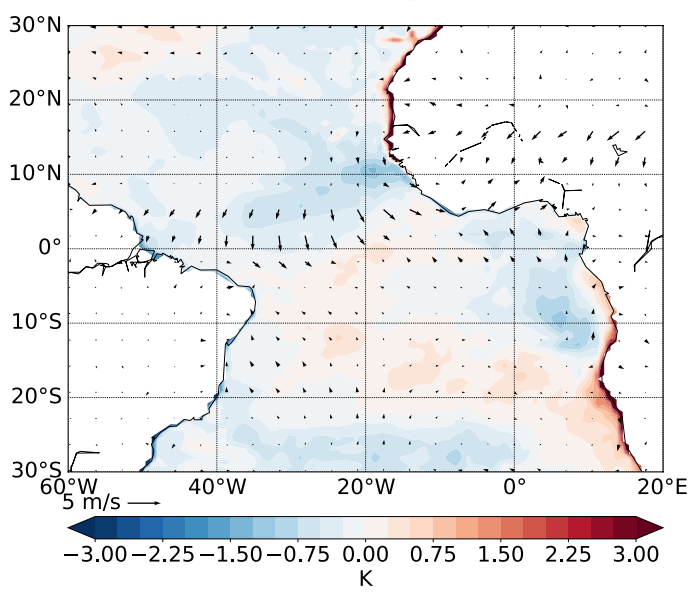

(d)

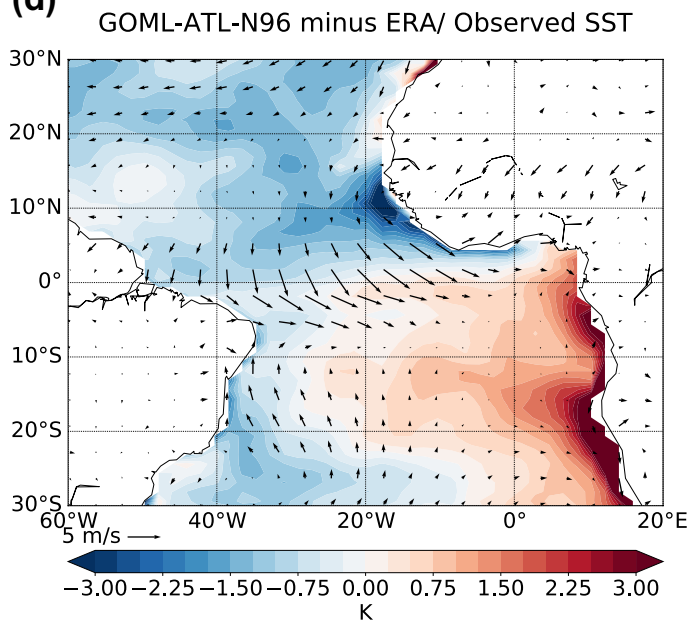

(f)

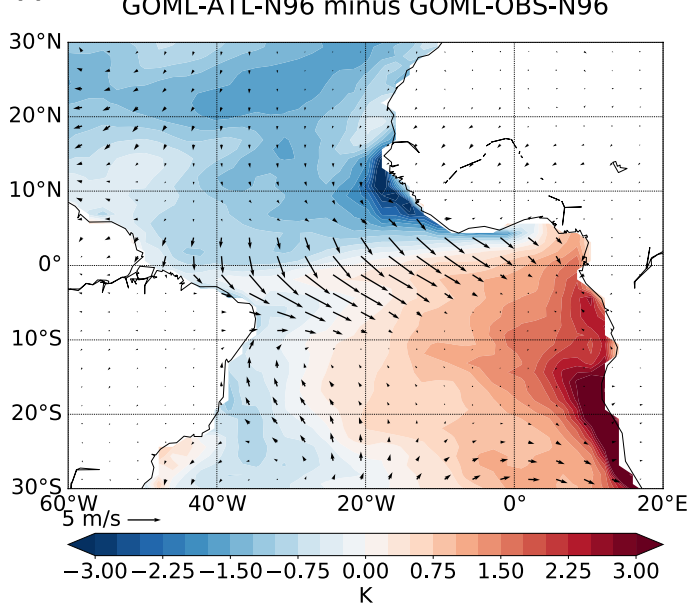

and b GOML-OBS, $\mathbf{c}$ GOML-GC2, and d GOML-ATL-N96. e shows the difference between GOML-GC2 and GOML-OBS and $\mathbf{f}$ shows the difference between GOML-ATL-N96 and GOML-OBS-N96 
that cools the eastern equatorial Atlantic (Okumura and Xie 2004; Hagos and Cook 2009). Reduced cross-equatorial southerlies, as seen in Fig. 8c, d, will therefore also reduce equatorial upwelling in fully coupled simulations, contributing to the warm bias.

The results here demonstrate that ocean mean state biases in the Atlantic are associated with a southward shift of the TRB in boreal spring, related to changes in the meridional temperature gradient, and equatorial wind biases, which also affect and respond to the position of the tropical rain belt. Further investigation is required to investigate the complex interplay of factors, including precipitation, wind and SST biases that develop over the Atlantic during boreal spring in coupled simulations.

\subsection{Overestimation of rainfall during the August LDS}

In order to understand the overestimation of rainfall during the August LDS, vertical cross sections of zonal wind and vertical velocity compare regions of ascent and descent and rainfall in the GOML simulations with ERA-I reanalysis over the LDS region (Fig. 9). For August, ERA-I and GOML-OBS show similar patterns, in agreement with Nicholson (2009), Nicholson (2013) and James et al. (2018). Two regions of ascent are identified: one centred around $20^{\circ} \mathrm{N}$ (shifted slightly south in GOML-OBS) and another deeper region centred around $10^{\circ} \mathrm{N}$. The ascent at $20^{\circ} \mathrm{N}$ corresponds to the surface ITCZ (Nicholson 2009), while most of the rainfall is associated with the ascent at $10^{\circ} \mathrm{N}$, just north of the coastline. Both ERA-I and GOML-OBS have a weaker, more southerly rainfall peak compared with GPCP (dashed black line). The southward shift of the northern region of shallow ascent in all GOML simulations when compared with ERA-I may indicate that the surface ITCZ does not propagate far enough north. This may be related to the dry bias over the Sahel in JJA seen in both GA6-OBS and GC2-GC2 (see Supplementary Information) and the southward shift of the TRB in Fig. 7.

Descent over the northern Gulf of Guinea (Fig. 9a, b), which encroaches onto the southern part of West Africa, caps the shallow ascent along the coastline, and gives lower rainfall totals here. ERA-I and GOML-OBS show reduced precipitation along the coast, consistent with the LDS; shallow ascent prevails at the coast due to upper level descent. While GOML-GC2 and GOML-ATL-N96 (Fig. 9c, d) also capture the two main regions of ascent, they do not capture the region of descent encroaching onto the coastline. The ascent at the coastline is deeper, associated with a second rainfall peak on the coast, consistent with earlier results showing rainfall along the coastline in August in GOML-GC2 and GOML-ATL-N96 (Fig. 6a). The ascent in GOML-ATL-N96 at $10^{\circ} \mathrm{N}$ is weaker than in GOML-GC2, but this is a consequence of resolution rather than ocean mean state biases (see Supplementary Information). All simulations show a southward shift in the position of the African Easterly Jet (AEJ) compared to ERA-I: while in ERA-I (and Nicholson 2013) the axis of the AEJ is north of the main region of ascent, the GOML simulations show the axis of the AEJ co-located with the ascent at $10^{\circ} \mathrm{N}$. James et al. (2018) also identified a southward shift in the AEJ in GC2. This may indicate errors in the representation of the meridional temperature gradient, as Parker and Diop-Kane (2017) report that the AEJ is in approximate thermal wind balance with the lower tropospheric temperature gradient. Convection occurs more frequently south of the AEJ than north of the AEJ (Parker and Diop-Kane 2017), hence a southward bias in the position of the AEJ is consistent with the southward shift of the TRB in Fig. 7 in all simulations. Since GOML-OBS, GOML-GC2 and GOML-ATL-N96 all contain a southward bias in AEJ position and TRB position, yet only those simulations forced with Atlantic SST bias (GOML-GC2 and GOML-ATL-N96, Fig 9c, d) fail to capture the LDS, this supports the conclusion from Fig. $7 d$ that the LDS in August is associated with local factors. The stronger AEJ in GOML-ATL-N96 compared with GOML$\mathrm{GC} 2$ and GOML-OBS is not a consequence of resolution (see Supplementary Information, Figure S4), and is driven by other factors.

Figure 9 suggests that the descent above $500 \mathrm{hPa}$ and limited ascent along the coastline is associated with reduced rainfall over the coastline during August in ERA-I and GOML-OBS. In GOML simulations forced by the coupled model ocean mean state over the Atlantic (GOML-GC2 and GOML-ATL-N96) the region of descent is shifted south, the ascent along the coastline is deeper, and higher rainfall is seen along the coastline. Parker and Diop-Kane (2017) state that high pressure over the Gulf of Guinea extends onto the coastline in July-August, with the associated descent inhibiting rainfall, leading to the LDS. Over the northern Gulf of Guinea, GOML-GC2 and GOML-ATL-N96 exhibit lower mean sea-level pressure in August, compared with GOMLOBS/GOML-OBS-N96 (not shown). Although it was not quantitatively shown, Odekunle and Eludoyin (2008) and Odekunle (2010) also proposed that increased static stability over the coastline limits convection and leads to the reduced rainfall associated with the LDS. They suggest that this increased static stability results from the cool SSTs along this coastline during the boreal summer, due to local upwelling and the advection of cold upwelled waters from other regions. Similarly, Parker and Diop-Kane (2017) note that the LDS is weak or absent where warm onshore waters persist, for example, to the east around the Niger delta in Nigeria and off the coast of Liberia. Upwelling between the Liberia/Ivory Coast border and Ghana is a consequence of the non-linear dynamics of the Guinea Current and its 
(a)

Vertical Velocity over $10^{\circ} \mathrm{W}-2^{\circ} \mathrm{E}$ in August from ERA-Interim

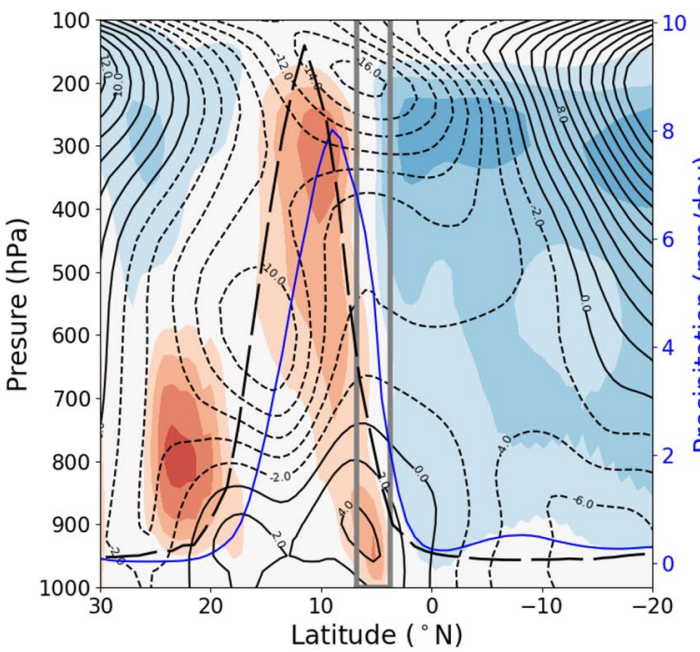

$\begin{array}{lllllll}-1.4 & -1.0 & -0.6 & -0.2 & 0.4 & 0.8 & 1.2\end{array}$

Mean vertical velocity $\left(10^{-2} \mathrm{~ms}^{-1}\right)$

(c)

Vertical Velocity over $10^{\circ} \mathrm{W}-2^{\circ} \mathrm{E}$ in August from GOML-GC2
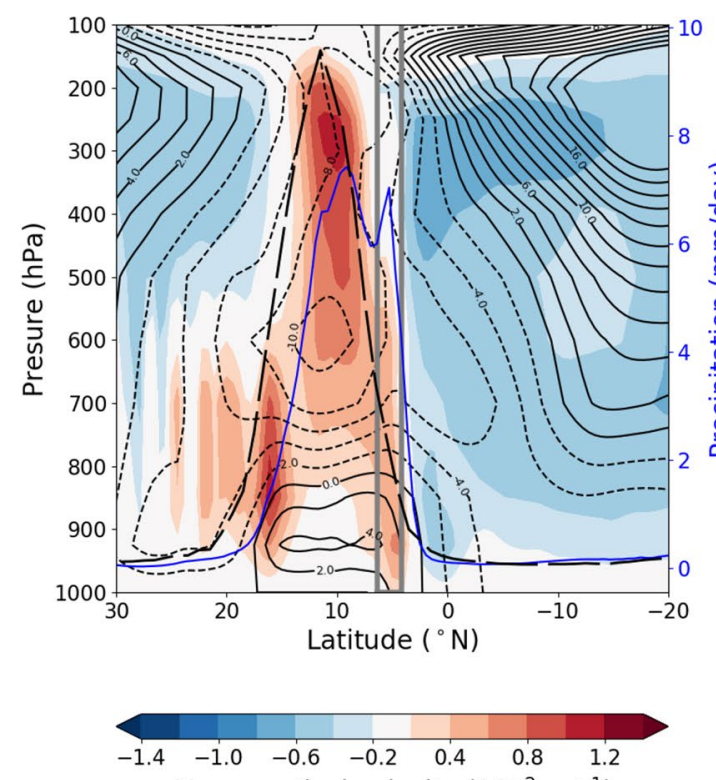

Mean vertical velocity $\left(10^{-2} \mathrm{~ms}^{-1}\right)$

Fig. 9 Vertical cross section of the mean vertical velocity in August (coloured contours), mean zonal wind velocity (solid/dashed contours for positive/negative values respectively) and mean precipitation (solid blue line) from ERA-I (a), GOML-OBS (b), GOML-GC2 (c)

detachment from the coast, while upwelling east of Ghana is driven by local winds (Djakouré et al. 2017), hence reduced upwelling in coupled models is consistent with poor (b)

Vertical Velocity over $10^{\circ} \mathrm{W}-2^{\circ} \mathrm{E}$ in August from GOML-OBS
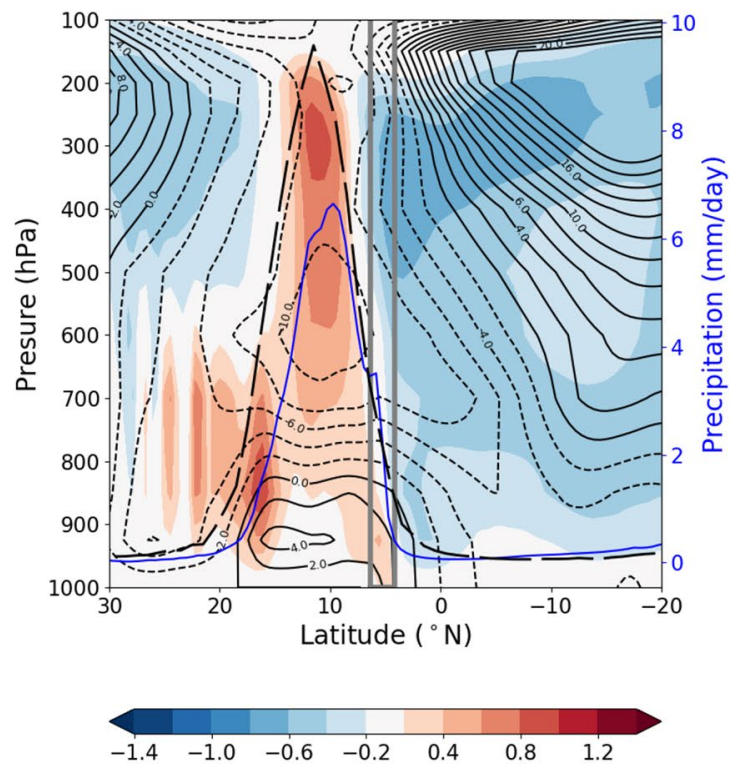

Mean vertical velocity $\left(10^{-2} \mathrm{~ms}^{-1}\right)$

(d)

Vertical Velocity over $10^{\circ} \mathrm{W}-2^{\circ} \mathrm{E}$ in August from GOML-ATL-N96
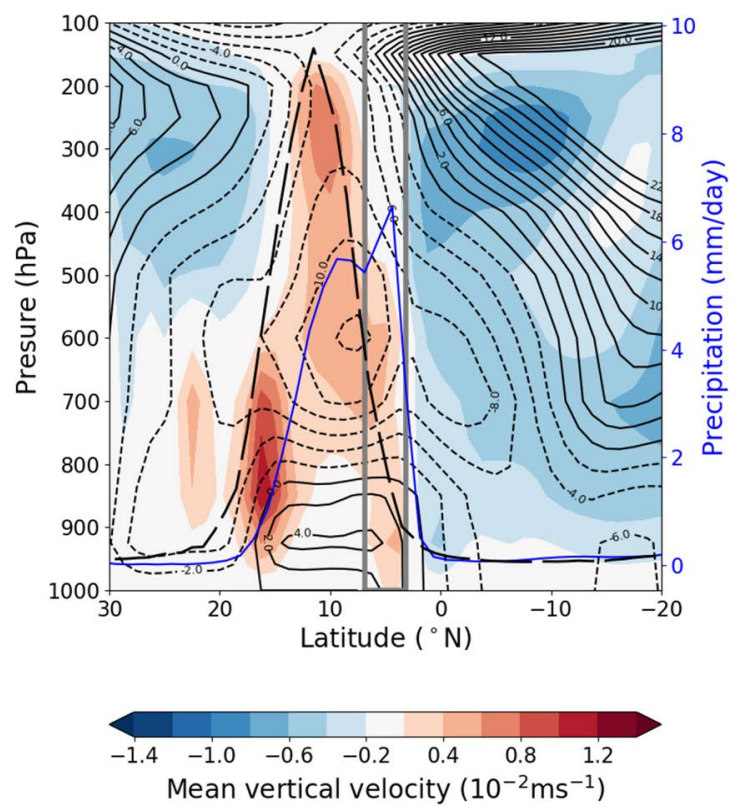

and GOML-ATL-N96 (d) averaged over $10^{\circ} \mathrm{W}$ to $2^{\circ} \mathrm{E}$. The dashed black line shows the GPCP precipitation. The grey lines mark the coastline region (where land sea fraction is between 5 and 95\%). For details of dates and simulations see Table 1

representation of the Guinea Current and the westerly wind biases present over this region from June-August (result not shown). 
Figure 9 demonstrates that when GOML is constrained to the observed ocean state, with cooler SSTs in August (Fig. 1d-f), upper level descent reduces rainfall along the coastline, whereas the introduction of GC2 ocean mean state biases, including a warm bias over the northern Gulf of Guinea (Fig. 1j-1), leads to ascent along the coastline, preventing occurrence of the LDS in those simulations. Further investigation, with additional simulations, is required to elucidate specific regions of influence and mechanisms.

\section{Discussion and conclusions}

Several configurations of the Met Office Unified Model (MetUM) were used to explore factors that influence the representation of the seasonal cycle of precipitation over the southern part of West Africa, which is unrealistically represented in coupled climate model simulations (Dunning et al. 2017). In addition to atmosphere-only (GA6) and fully coupled (GC2) configurations, we analyse simulations with the Global Ocean Mixed Layer (GOML) configuration. This novel model configuration is a useful tool for process-based studies as it enables us to cleanly isolate the role of air-sea interactions, and to examine the impact of different mean ocean states, while maintaining air-sea coupling (Hirons et al. 2015).

We have shown differences in the balance of ascent and descent over the southern part of West Africa in simulations that correctly or incorrectly represent the LDS, adding support to previous studies that suggested that the seasonal reduction in rainfall observed over the southern part of West Africa during the LDS is related to increased static stability, which prevents the development of convection and thus inhibits precipitation (Odekunle and Eludoyin 2008).

All simulations underestimated rainfall over the southern part of West Africa in October. This meant that the second wet season, following the LDS, was not captured by any simulation. The presence of this bias in GA6-OBS and GC2-GC2 demonstrates that this bias is not a consequence of ocean mean-state biases nor the inclusion of air-sea coupling. James et al. (2018) show that GC2 also contains a dry bias across West Africa in September, October and November. This bias may be related to the dry bias further north across the Sahel in June-August in GC2 (James et al. 2018), which is also present in atmosphere-only simulations (Williams et al. 2015), including GA6 and a previous version, GA4 (Walters et al. 2017). Stratton et al. (2018) found that the JJA dry bias was reduced in a convection-permitting MetUM simulation which contained a realistic westward propagation of mesoscale convective systems, and produced more frequent heavy precipitation.

The warm SST biases over the south-east tropical Atlantic in GC2 prevail in many coupled climate models (Richter et al. 2012; Toniazzo and Woolnough 2014; Siongco et al. 2015). Other studies have identified the detrimental effect of these biases for reducing precipitation over the Sahel (Roehrig et al. 2013; Eichhorn and Bader 2017; Steinig et al. 2018). Here we have shown that these biases lead to an inaccurate representation of the seasonality of precipitation over a densely populated part of West Africa, where the seasonal cycle of rainfall is of high socio-economic importance. These biases inhibit accurate projections of future changes in rainfall amount and timing for the region that experiences the LDS. Further work is required to improve the representation of SST in the Atlantic, which will facilitate greater understanding of future changes in many aspects of the West African monsoon.

The pattern of SST and surface wind biases apparent in Fig. 8 is similar to that found by Richter and Xie (2008) and Richter et al. (2012), who state that continental precipitation biases that initiate westerly wind biases across the equatorial Atlantic, reducing equatorial upwelling, are a source of the SST biases in the equatorial Atlantic. Additionally, reduced strength of cross-equatorial southerlies may reduce equatorial upwelling, and contribute to warm SST biases. Along the Guinea coastline, low ocean model horizontal resolution may result in poor representation of the Guinea Current and upwelling, resulting in the warm bias in this region in GC2. Establishing the origin of SST biases is beyond the scope of the present study, but further work should examine such processes.

The additional GOML simulation performed with the coupled model ocean mean state over the Atlantic, and the observed ocean mean state over the Indian and Pacific Oceans, demonstrates that the discrepancies in simulations using coupled model ocean state are related to Atlantic Ocean SST biases, and adds credence to the proposed mechanisms. Further investigation, with additional simulations for example with coupled model ocean biases just over the south-east Atlantic Ocean, or the northern Gulf of Guinea, or with biases only in certain seasons, are required to further elucidate specific regions of influence and mechanisms, but is beyond the scope of this study.

One notable caveat is the lack of ocean dynamics in GOML, which means it is unable to simulate coupled modes of variability that rely on ocean dynamics (e.g. the El Niño Southern Oscillation, the Indian Ocean Dipole, Atlantic Niños). Thus we cannot capture any mean-state biases that are due to the rectification onto the mean state of erroneous teleconnections from these phenomena to West Africa. The similarity of GOML-GC2 and GC2-GC2 experiments suggests that biases in West African rainfall are linked to the mean state, not to variability, and thus this effect is small.

In summary, the overestimation of July-August rainfall in GC2 over the southern part of West Africa is not due to air-sea coupled physics on seasonal or sub-seasonal 
timescales, but rather is linked to ocean mean state biases in the Atlantic. While horizontal resolution plays some role, it is not the primary cause of the biases in this region. The key conclusions are:

- The atmosphere-only configuration of the MetUM simulates two wet seasons over the southern part of West Africa, with the correct timing of the first wet season and LDS. The fully coupled configuration of the MetUM does not exhibit a biannual regime, and instead places the peak of the one annual wet season during the expected LDS period, similar to the results from CMIP5 coupled models (Dunning et al. 2017). However, all MetUM configurations underestimate the magnitude of the second wet season, which was not seen in the wider CMIP5 ensemble.

- The Global Ocean Mixed Layer (GOML) configuration includes coupling to a high vertical resolution ocean, with computational costs similar to atmosphere-only models. GOML allows us to include air-sea interactions while constraining the ocean mean state. This isolates the role of coupling without introducing large systematic errors in SST. The inclusion of air-sea coupling has a minimal influence on the seasonal cycle of precipitation over the southern part of West Africa.

- Differences in the ocean mean state lead to differences in the seasonal cycle of precipitation over the southern part of West Africa. When ocean mean state biases from the coupled MetUM simulation (GC2) are introduced in GOML, the two wet seasons and the LDS are not captured, and rainfall is underestimated in late boreal spring and early boreal summer. Using GOML enables us to perform simulations with regional or global GC2 mean state, while retaining coupling.

- The underestimation of rainfall in May in simulations with the coupled model ocean mean state is related to a southward shift of the main tropical rain belt. Warm SST anomalies in the south eastern tropical Atlantic, and cool anomalies in the north and west alter the meridional temperature gradient and induce north-westerly wind biases between $0^{\circ} \mathrm{S}$ and $10^{\circ} \mathrm{S}$, which are associated with the southward shift of the tropical rain belt.

- In August, upper level descent caps the ascent along the coastline in reanalysis (ERA-Interim) and GOMLOBS, limiting the convection, resulting in the lower rainfall rates associated with the LDS. In GOML-GC2 and GOML-ATL-N96, the ascent along the coastline is not restricted, leading to deeper ascent and high rainfall rates. A number of studies have proposed that the cool SSTs near the Guinea coastline in boreal summer (see Figure 1) increase static stability, which inhibits convection and leads to the LDS (Odekunle and Eludoyin 2008; Odekunle 2010). Here introducing coupled model SST biases, including a warm anomaly along the Guinea coast in August, leads to enhanced ascent and rainfall in the LDS region.

- The GOML-ATL-N96 simulation, forced by the coupled model ocean state over the Atlantic, and observed ocean mean state elsewhere, exhibits similar behaviour to the simulations with the coupled model ocean state globally, indicating that the discrepancies discussed above are related to SST biases over the Atlantic Ocean and not remote teleconnections from SST biases in the Indian or Pacific Oceans.

In conclusion, ocean mean state biases over the Atlantic Ocean in GOML-GC2 (and GOML-ATL-N96) result in inaccurate representation of the seasonal cycle of precipitation over the southern part of West Africa, including the failure to correctly capture the Little Dry Season. This may suggest that the failure to capture the correct seasonal cycle in GC2 and other coupled climate models is associated with SST biases over the Atlantic Ocean. However, the coupled nature of the system renders it impossible to separate forcing from response, and the biases could be result of a different chain of processes. Further work is required to robustly identify the mechanisms via which the ocean mean state biases and the rainfall seasonality interact, and identify the sources of the SST biases and model modifications which could act to reduce such biases.

Acknowledgements Assembly of MetUM-GOML and development of MC-KPP was supported by the National Centre for Atmospheric Science. GOML simulations were performed on ARCHER, the UK national supercomputing facility. Data storage and processing facilities were provided by JASMIN (http://www.jasmin.ac.uk).

Caroline M. Wainwright is supported with funding from a Natural Environment Research Council (NERC) PhD Studentship through the SCENARIO Doctoral Training Partnership grant NE/L002566/1.

Linda C. Hirons' and Andrew G. Turner's contribution to the research has been supported by the Natural Environment Research Council (NERC) - Department for International Development (DfID) funded Improving Model Processes for African Climate (IMPALA) project (NE/M017222/1), as part of the Future Climate for Africa (FCFA) programme. Funding was also received from the National Centre for Atmospheric Science (NCAS), a collaborative centre of the Natural Environmental Research Council (NERC), under contract R8/ H12/83/001.

Nicholas P. Klingaman's contribution to the research was supported by a NERC Independent Research Fellowship (NE/L010976/1).

Richard P. Allan has received funding from the National Centre for Earth Observation and the European Union 7th Framework Programme (FP7/2007-2013) under grant agreement 603502 (EU project DACCIWA: Dynamics-aerosol-chemistry-cloud interactions in West Africa).

Emily Black's contribution to the research has been supported by the National Centre for Atmospheric Science (Climate division) ACREW project, which is supported by NERC and the Global Challenges Research Fund. She also gratefully acknowledges support from the NERC/DFID BRAVE project (NE/M008983/1), the NERC/ DFID HyCristal project (NE/M020371/1) and the Global Challenges Research Fund project, SatWIN-ALERT (NE/R014116/1). 
We are grateful to the Mars Wrigley Confectionery research team for stimulating discussions on the wider context and applications of this work.

Open Access This article is distributed under the terms of the Creative Commons Attribution 4.0 International License (http://creativeco mmons.org/licenses/by/4.0/), which permits unrestricted use, distribution, and reproduction in any medium, provided you give appropriate credit to the original author(s) and the source, provide a link to the Creative Commons license, and indicate if changes were made.

\section{References}

Adejuwon JO, Odekunle TO (2006) Variability and the Severity of the "Little Dry Season" in southwestern Nigeria. J Clim 19(3):483-493

Chang P, Zhang R, Hazeleger W, Wen C, Wan X, Ji L, Haarsma RJ, Breugem WP, Seidel H (2008) Oceanic link between abrupt changes in the North Atlantic Ocean and the African monsoon. Nat Geosci 1(7):444

Chineke TC, Jagtap SS, Nwofor O (2010) West African monsoon: is the August break "breaking" in the eastern humid zone of Southern Nigeria? Clim Change 103(3-4):555-570

Cook KH, Vizy EK (2006) Coupled model simulations of the West African monsoon system: twentieth-and twenty-first-century simulations. J Clim 19(15):3681-3703

Dee D, Uppala S, Simmons A, Berrisford P, Poli P, Kobayashi S, Andrae U, Balmaseda M, Balsamo G, Bauer P et al (2011) The ERA-Interim reanalysis: configuration and performance of the data assimilation system. Q J R Meteorol Soc 137(656):553-597

DeMott CA, Klingaman NP, Woolnough SJ (2015) Atmosphere-ocean coupled processes in the Madden-Julian oscillation. Rev Geophys 53(4):1099-1154

Dike VN, Shimizu MH, Diallo M, Lin Z, Nwofor OK, Chineke TC (2015) Modelling present and future African climate using CMIP5 scenarios in HadGEM2-ES. Int J Climatol 35(8):1784-1799

Dixon RD, Daloz AS, Vimont DJ, Biasutti M (2017) Saharan heat low biases in CMIP5 models. J Clim 30(8):2867-2884

Djakouré S, Penven P, Bourlès B, Koné V, Veitch J (2017) Respective roles of the Guinea current and local winds on the coastal upwelling in the Northern Gulf of Guinea. J Phys Oceanogr 47(6):1367-1387

Dunning CM, Black EC, Allan RP (2016) The onset and cessation of seasonal rainfall over Africa. J Geophys Res Atmos 121(19):11

Dunning CM, Allan RP, Black E (2017) Identification of deficiencies in seasonal rainfall simulated by CMIP5 climate models. Environ Res Lett 12(11):114001

Eichhorn A, Bader J (2017) Impact of tropical Atlantic sea-surface temperature biases on the simulated atmospheric circulation and precipitation over the Atlantic region: An ECHAM6 model study. Clim Dyn 49(5-6):2061-2075

Flato G, Marotzke J, Abiodun B, Braconnot P, Chou SC, Collins WJ, Cox P, Driouech F, Emori S, Eyring V, et al (2013) Evaluation of climate models. In: Climate change 2013: the physical science basis. contribution of working group I to the fifth assessment report of the intergovernmental panel on climate change. Climate Change 2013, vol 5, pp 741-866

Găinuşă-Bogdan A, Hourdin F, Traore AK, Braconnot P (2017) Omens of coupled model biases in the CMIP5 AMIP simulations. Clim Dyn :1-15

Hagos SM, Cook KH (2009) Development of a coupled regional model and its application to the study of interactions between the West
African monsoon and the eastern tropical Atlantic Ocean. J Clim 22(10):2591-2604

Hawcroft M, Haywood JM, Collins M, Jones A, Jones AC, Stephens G (2017) Southern Ocean albedo, inter-hemispheric energy transports and the double ITCZ: global impacts of biases in a coupled model. Clim Dyn 48(7-8):2279-2295

Herrmann SM, Mohr KI (2011) A continental-scale classification of rainfall seasonality regimes in Africa based on gridded precipitation and land surface temperature products. J Appl Meteorol Climatol 50(12):2504-2513

Hirons L, Klingaman N, Woolnough S (2015) MetUM-GOML: a nearglobally coupled atmosphere-ocean-mixed-layer model. Geosci Model Dev 8:363-379

Huffman GJ, Adler RF, Morrissey MM, Bolvin DT, Curtis S, Joyce R, McGavock B, Susskind J (2001) Global precipitation at onedegree daily resolution from multisatellite observations. J Hydrometeorol 2(1):36-50

Hwang YT, Frierson DM (2013) Link between the double-intertropical convergence zone problem and cloud biases over the southern ocean. Proc Nat Acad Sci 110(13):4935-4940

James R, Washington R, Abiodun B, Kay G, Mutemi J, Pokam W, Hart N, Artan G, Senior C (2018) Evaluating climate models with an African lens. Bull Amer Meteor Soc 99:313-336. https://doi. org/10.1175/BAMS-D-16-0090.1

Lauer A, Jones C, Eyring V, Evaldsson M, Hagemann S, Mäkelä J, Martin G, Roehrig R, Wang S (2018) Process-level improvements in CMIP5 models and their impact on tropical variability, the southern ocean, and monsoons. Earth Syst Dyn 9:33-67. https:// doi.org/10.5194/esd-9-33-2018

Liebmann B, Bladé I, Kiladis GN, Carvalho LM, Senay GB, Allured D, Leroux S, Funk C (2012) Seasonality of African precipitation from 1996 to 2009. J Clim 25(12):4304-4322

Martin ER, Thorncroft C (2015) Representation of african easterly waves in cmip5 models. J Clim 28(19):7702-7715. https://doi. org/10.1175/JCLI-D-15-0145.1

Mathon V, Laurent H, Lebel T (2002) Mesoscale convective system rainfall in the Sahel. J Appl Meteorol 41(11):1081-1092

Mohino E, Rodríguez-Fonseca B, Mechoso CR, Gervois S, Ruti P, Chauvin F (2011) Impacts of the tropical Pacific/Indian Oceans on the seasonal cycle of the West African monsoon. J Clim 24(15):3878-3891

Nicholson SE (2009) A revised picture of the structure of the "monsoon" and land ITCZ over West Africa. Clim Dyn 32(7-8):1155-1171

Nicholson SE (2013) The West African Sahel: a review of recent studies on the rainfall regime and its interannual variability. ISRN Meteorol 2013:453521. https://doi.org/10.1155/2013/453521

Odekunle T (2007) Predicting the variability and the severity of the "Little Dry Season" in Southwestern Nigeria. Ife J Sci $9(1): 88-102$

Odekunle TO (2010) An assessment of the influence of the inter-tropical discontinuity on inter-annual rainfall characteristics in Nigeria. Geogr Res 48(3):314-326

Odekunle TO, Eludoyin A (2008) Sea surface temperature patterns in the Gulf of Guinea: their implications for the spatio-temporal variability of precipitation in West Africa. Int J Climatol 28(11):1507-1517

Okumura Y, Xie SP (2004) Interaction of the Atlantic equatorial cold tongue and the African Monsoon. J Clim 17(18):3589-3602. https://doi.org/10.1175/1520-0442(2004)017<3589:IOTAE $\mathrm{C}>2.0 . \mathrm{CO} ; 2$

Parker D, Diop-Kane M (2017) Meteorology of tropical West Africa: the forecaster's handbook. Wiley, New York 
Reynolds RW, Smith TM, Liu C, Chelton DB, Casey KS, Schlax MG (2007) Daily high-resolution-blended analyses for sea surface temperature. J Clim 20(22):5473-5496

Richter I, Xie SP (2008) On the origin of equatorial Atlantic biases in coupled general circulation models. Clim Dyn 31(5):587-598

Richter I, Xie SP, Wittenberg AT, Masumoto Y (2012) Tropical Atlantic biases and their relation to surface wind stress and terrestrial precipitation. Clim Dyn 38(5-6):985-1001

Richter I, Xie SP, Behera SK, Masumoto Y (2014) Equatorial Atlantic variability and its relation to mean state biases in CMIP5. Clim Dyn 42(12):171-188

Roehrig R, Bouniol D, Guichard F, Hourdin F, Redelsperger JL (2013) The present and future of the West African monsoon: a processoriented assessment of CMIP5 simulations along the AMMA transect. J Clim 26(17):6471-6505

Shonk JK, Guilyardi E, Toniazzo T, Woolnough SJ, Stockdale T (2018) Identifying causes of western pacific itcz drift in ecmwf system 4 hindcasts. Clim Dyn 50(3-4):939-954

Siongco AC, Hohenegger C, Stevens B (2015) The Atlantic ITCZ bias in CMIP5 models. Clim Dyn 45(5-6):1169-1180

Smith DM, Murphy JM (2007) An objective ocean temperature and salinity analysis using covariances from a global climate model. $\mathrm{J}$ Geophys Res 112:C02022. https://doi.org/10.1029/2005JC003172

Sperber KR, Cusiner E, Kitoh A, Mechoso CR, Moise A, MoufoumaOkia W, Schiro K, Turner AG (2017) Modelling monsoons. In: The Global monsoon system: research and forecast. World Scientific, pp 79-101

Steinig S, Harlaß J, Park W, Latif M (2018) Sahel rainfall strength and onset improvements due to more realistic Atlantic cold tongue development in a climate model. Sci Rep 8(1):2569

Stratton RA, Senior CA, Vosper SB, Folwell SS, Boutle IA, Earnshaw PD, Kendon E, Lock AP, Malcolm A, Manners J et al (2018) A Pan-African convection-permitting regional climate simulation with the met office unified model: CP4-Africa. J Clim 31(9):3485-3508

Sultan B, Janicot S (2003) The West African monsoon dynamics. Part II: The "preonse" and "onset" of the summer monsoon. J Clim 16(21):3407-3427
Taylor KE, Stouffer RJ, Meehl GA (2012) An overview of CMIP5 and the experiment design. Bull Am Meteorol Soc 93(4):485-498

Toniazzo T, Woolnough S (2014) Development of warm SST errors in the southern tropical Atlantic in CMIP5 decadal hindcasts. Clim Dyn 43(11):2889-2913

Valcke S, Caubel A, Declat D, Terray L (2003) Oasis3 ocean atmosphere sea ice soil user's guide. CERFACS Tech Rep TR/ CMGC/03/69, Toulouse, France p 85 pp

Vellinga M, Roberts M, Vidale PL, Mizielinski MS, Demory ME, Schiemann R, Strachan J, Bain C (2016) Sahel decadal rainfall variability and the role of model horizontal resolution. Geophys Res Lett 43(1):326-333

Voldoire A, Exarchou E, Sanchez-Gomez E, Demissie T, Deppenmeier AL, Frauen C, Goubanova K, Hazeleger W, Keenlyside N, Koseki S, Prodhomme C, Shonk J, Toniazzo T, Traoré AK (2019) Role of wind stress in driving SST biases in the tropical atlantic. Clim Dyn. https://doi.org/10.1007/s00382-019-04717-0

Walters D, Boutle I, Brooks M, Thomas M, Stratton R, Vosper S, Wells H, Williams K, Wood N, Allen T et al (2017) The met office unified model global atmosphere 6.0/6.1 and JULES global land 6.0/6.1 configurations. Geosci Model Dev 10(4):1487

Whittleston D, Nicholson S, Schlosser A, Entekhabi D (2017) Climate models lack jet-rainfall coupling over West Africa. J Clim 30(12):4625-4632

Williams K, Harris C, Bodas-Salcedo A, Camp J, Comer R, Copsey D, Fereday D, Graham T, Hill R, Hinton T et al (2015) The met office global coupled model 2.0 (GC2) configuration. Geosci Model Dev 8(5):1509

Publisher's Note Springer Nature remains neutral with regard to jurisdictional claims in published maps and institutional affiliations. 